\title{
Chemical reaction engineering, process design and scale-up issues at the frontier of synthesis: flow chemistry
}

\section{Ilenia Rossetti *, Matteo Compagnoni}

Dip. Chimica, Università degli Studi di Milano, INSTM Unit Milano-Università and CNR-ISTM, via Golgi 19, 20133 Milano, Italy; e-Mail: ilenia.rossetti@unimi.it

* Author to whom correspondence should be addressed; e-Mail: ilenia.rossetti@unimi.it; Tel.: +39-02-50314059; Fax: +39-02-50314300.

\begin{abstract}
Flow chemistry has been proposed in modern organic chemistry as a mean for process intensification, to improve the control over reaction performance and to achieve higher yield. However, many open issues can be evidenced regarding the true possibility of scale-up, as well as currently lacking information for process design and economical evaluation. This review proposes some recent examples of flow synthesis deepening in particular the scale-up and engineering issues. Required information is evidenced, as well as some transport and kinetic data required for the practical implementation of the results.
\end{abstract}

Keywords: Flow chemistry; Chemical reaction engineering; Microreactors; Process design; Reactor scale-up.

\section{Introduction}

Flow chemistry and microreactors technology are emerging and fascinating topics, which put in contact Chemical Engineering, Organic Synthesis and Green Chemistry. Therefore, in itself flow chemistry is a consistently interdisciplinary topic, needing a fine tuning between fluid-dynamics, heat and mass transfer, chemical reactivity and reactors design [1].

Batch processes are commonly used in fine, specialty and pharmaceutical chemistry due to their versatility, flexible production planning and scheduling. They may also be preferable due to regulatory problems, where traceability imposes to easily recall specific batches of products. On the other hand, they are often difficult to scale-up because of heat and mass transfer problems. In addition, they require significant intermediate storage capacity between process stages, resulting in large inventories of feedstock organic chemicals and sensitive intermediates. Continuous systems typically require smaller equipment volumes than batch ones and have a lower need for human intervention. Particularly referring to pharma industry, the time-to-market of a successful recipe is even more important than for base chemicals, due to the volatility of the products life. Pharma product development is regulatory driven and result of clinical phases determines market access. Thus, the possibility to access sufficient material 
for clinical trials with minimum efforts is a key for competitiveness. Therefore, the possibility of continuous operations offers many advantages: lower costs, reduced waste, decreased time-to-market for new drugs. Continuous flow reactors can deliver significantly higher yields, while solvent and energy waste can be decreased up to $90 \%$ [2].

It is also suggested that a general improvement of safety and sustainability of the fine-chemicals and pharma industries may take place. Indeed, typical processes have been developed to cope with regulation and safety issues based on the present technology. If intrinsically safer production processes may be developed, this may open the way to synthetic routes characterized by lower E-factor (i.e. $\mathrm{kg}$ of waste per kg of product, typically higher than 25 for such applications) [3]. In general, continuous processes seem to have a "greener" footprint than the analogous batch ones [4]. Process intensification is another goal, achievable by broadening the process conditions window and by better integrating different process steps [5].

Furthermore, the complex channels structure in microreactors generates secondary flow structures at high flow velocities, which lead to very efficient and fast mixing. Transport limitations are therefore reduced with respect to conventional reactors configurations. This leads to important applications in process intensification. It is considered that $c a .20 \%$ of the organic reactions inventory can effectively take advantage of improved mass and heat transfer for productivity, selectivity and/or safety reasons [6].

Another interesting feature is represented by the widening window of operating conditions made possible by flowing systems. These include unconventionally high temperature, pressure and the use of high-boiling solvents $[7,8]$. Some of the most interesting features of flow chemistry have been recently summarised by different authors [9-14]. The goal of this review is to cope with open issues and nonintuitive concepts for organic synthetic chemists, who increasingly deal with microreactors. For this purpose, the material is here organized by issue (e.g. transport phenomena, scale-up, safety, etc.), rather than for type of reaction.

\section{Examples and case studies}

A survey on the type of reactions that may be suitable for turning from batch to continuous processes has been considered. Basically, some classes of reactions may take advantage of microreactors and flow conditions: 1) Extremely fast reactions, usually carried out under mass (and/or heat transfer) regime, may be exploited by improving mixing and in general transport phenomena. Also, improved heat transfer should effectively prevent hot spots formation. Examples may be organometallic reactions; 2) Kinetically controlled, rapid reactions, where a strict control over temperature and residence time may improve selectivity (e.g. coupling reactions); 3) Hazardous reactions that may take place in more controlled conditions by using flowing systems, which also limit hazards due to decreased volumes [1,3]. 
Other classifications have been proposed in terms of reaction, phases or kinetics [15]. Of course, the final choice on the application of some continuous flow unit operations, or the whole transformation into a continuous process should be carefully based on economical evaluation. Interesting examples relative to drug development are proposed by Roberge et al. [16]. Results relative to reaction paths unrealizable in batch mode are also presented [17]. Finally, flow chemistry has been very effectively described as a way to expand the process window $[11,12]$.

\subsection{Fine chemicals and drugs synthesis}

The preparation of drugs and pharmaceutical active ingredients is usually carried out in batch or semicontinuous mode. This choice is usually based on the number of steps required (6 to 10), the low production volume, the need of differentiation and the short lifetime of the products. However, advantages of continuous flow synthesis are becoming evident, so that many pharma industries are setting up fully or partially continuous syntheses. In this case, there is a rapid need for scale-up at different levels, from lab synthesis, to drug testing and approval, to commercialization, and continuous flow synthesis offers many advantages from this point of view. Furthermore, increased throughput allows a lower footprint and process intensification [18]. Some successful examples are rapidly summarised in the following.

For safe operations in a cyclopropanation using dimethylsulfoxonium methylide at high temperatures, continuous operation was found more suitable for safe scale-up by carrying out the reaction at or below room temperature [19] (Scheme 1).
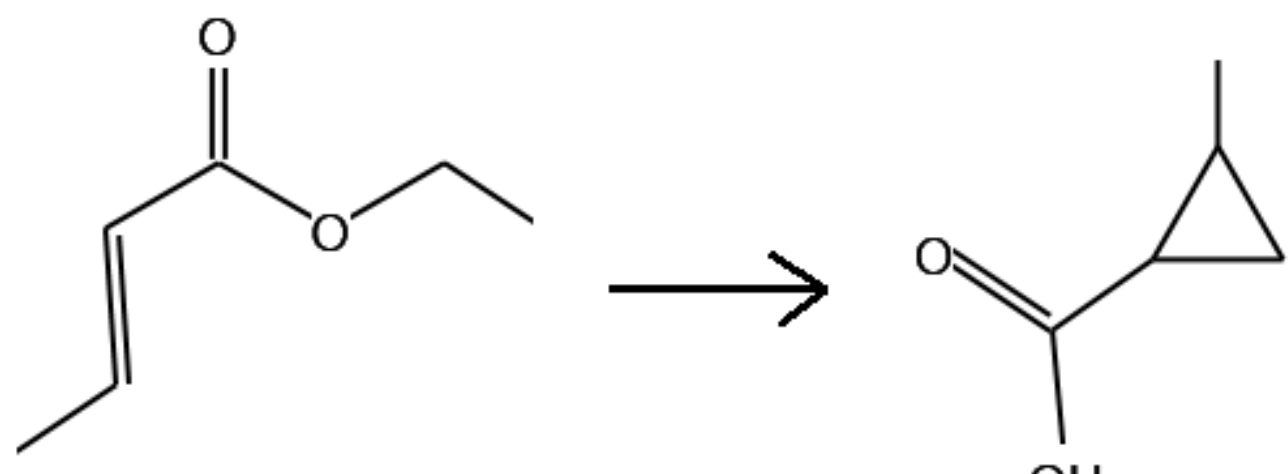

$\mathrm{OH}$

Scheme 1. Example of cyclopropanation reaction [19].

In the field of molecular biology many oligonucleotides are synthesized in small amount for gene analysis, but kilograms are needed for therapeutic scope and nontherapeutic applications such as anticounterfeiting markers [20]. Scale-up or numbering up is proposed for the scope. 
Transport limitation issues must be considered in lab operations when a change in product yield with mixing speed, or addition method, or the position of a feed stream, scale-up to a vessel with different geometry, or holding time before workup. These effects may imply the need of more efficient mixing and heat transfer to ensure better performance. Some examples have been reviewed by Anderson [21] and large scale production have been also proposed [22,23]. Thales Nanotech's X-Cube Flash reactor [24], operating continuously up to 200 bar and $350{ }^{\circ} \mathrm{C}$, was successfully applied for different reactions.

Flow chemistry applied to the synthesis of natural products has been extensively reviewed [25].

The Fukuyama reaction has been tested in continuous mode, allowing the conversion of thioesters to aldehydes with good selectivity. In some cases, however, negligible productivity was observed, possibly due to the Pd poisoning by the thiole. Some regeneration trials by washing were also attempted [26]. Many other Pd-catalysed reactions are reported by D. Astruc [27], including the Heck, Sonogashira, Suzuki, Stille, Negishi, Hiyama, Corriu-Kumada, Tsuji-Trost and Ullmann reactions (Scheme 2). Different strategies are proposed for the synthesis and stabilization of nanoparticles, in case bimetallic $\mathrm{Au}-\mathrm{Pd}$ with core-shell structure. The combination with ionic liquids is also discussed.
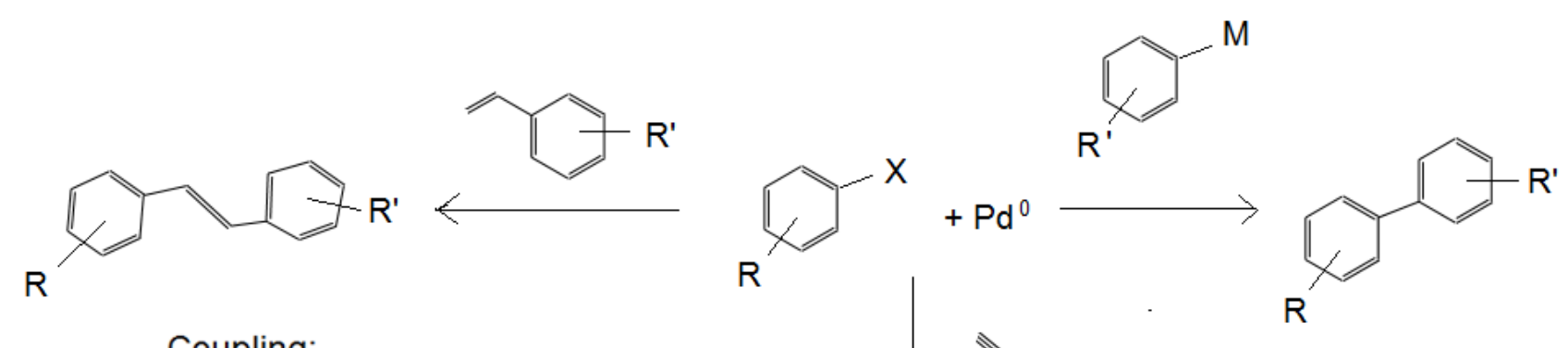

$$
\begin{aligned}
& \text { Coupling: } \\
& \text { Suzuki } \mathrm{M}=\mathrm{B}(\mathrm{OH})_{2} \\
& \text { Stille } \mathrm{M}=\mathrm{SnBu}{ }_{3} \\
& \text { Hiyama } \mathrm{M}=\mathrm{Si}(\mathrm{OR})_{3} \\
& \text { Negishi } \mathrm{M}=\mathrm{ZnX} \\
& \text { Kumada } \mathrm{M}=\mathrm{MgX}
\end{aligned}
$$

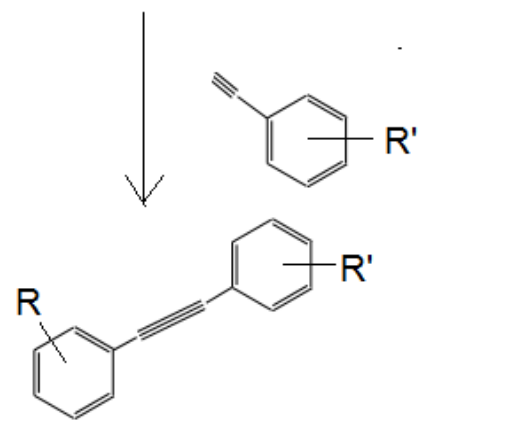

Scheme 2. Examples of Pd-catalysed coupling reactions [28]. $\mathrm{R}=$ substituting group; $\mathrm{Bu}=$ butyl.

Microwave (MW) assisted metathesis reactions and cross-coupling processes were reported in a Pdcoated capillary placed within the cavity of a single mode MW reactor [29]. The Pd films showed very porous, with ca. $6 \mu \mathrm{m}$ thickness and sufficient robustness for the scope. They showed excellent catalyst for Suzuki-Miyama and Heck reactions, with satisfactory results in less than one minute residence time. Another example reports a thin layer of gold for MW irradiation of a solid-supported catalyst in a Suzuki coupling using a continuous flow capillary reactor (Fig. 1) [30]. The strong absorption of a thin layer of gold on the outer surface of the capillary enabled effective heating of the catalyst, enhancing the rate of 
reaction. Yields greater than $70 \%$ were achieved, with catalyst/reactant contact times of less than $60 \mathrm{~s}$. MW-assisted Suzuki-Miyaura coupling using an encapsulated palladium catalyst has been also proposed [31]. The direct focused MW heating was coupled with an external cooling source. This enabled a lower bulk temperature with significant improvements in the overall yield and purity of the reaction products, together with prolonged lifetime and enhanced reactivity. In general, the sum of the advantages of microreactors and the activation of MWs improves significantly the productivity in most cases [32,33].

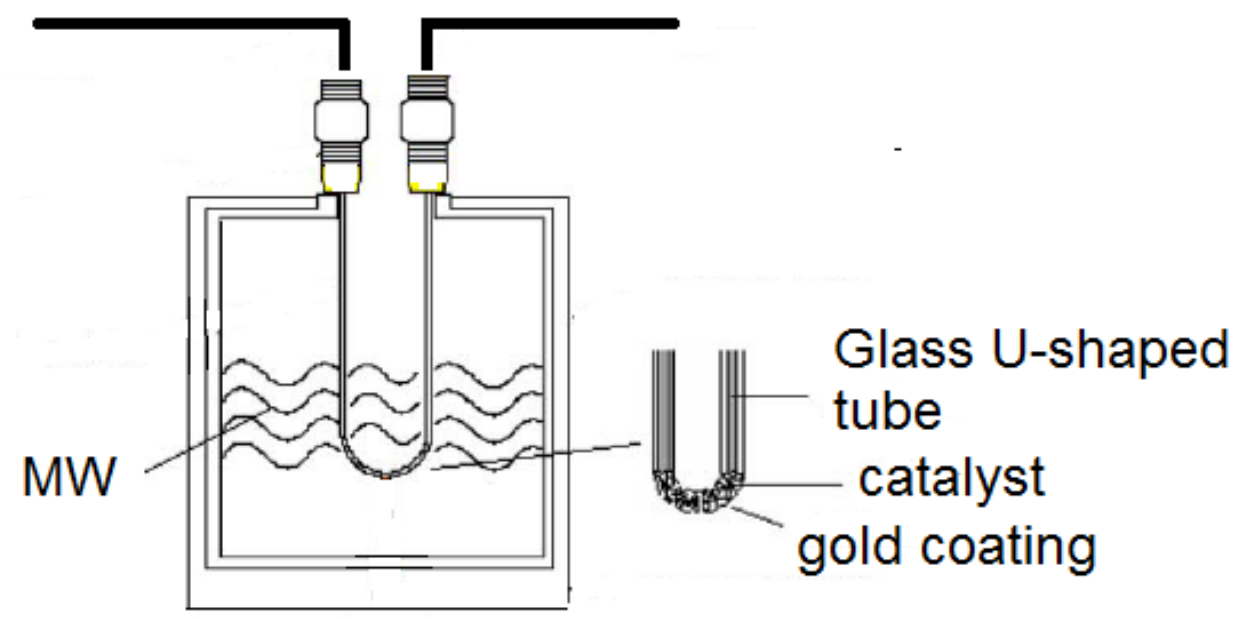

Figure 1. MW assisted Suzuki coupling reactions in glass capillary covered by gold for local heating [30].

The cyclodehydration of aminodienones and the continuous processing of pyridines was also compared in a microreactor fitted with a pressurization module and conductive heating, with respect to batch mode, with very good yields in short residence time [34]. For instance, conversion $>98 \%$ was attained in 2-4 min residence time depending on the selected substituents, leading to minimum yield of $78 \%$ in the case of ethyl and p-chlorophenyl substituents and a maximum $97 \%$ in the case of ethylphenyl substituents. As well, improved selectivity is reported for the Fischer indole synthesis of 7ethyltryptophol under flow conditions [35]. This led to total yield up to 50\% after purification, with respect to yields lower by $5-10 \%$ at best in batch mode. The reaction times and residence times were of similar order of magnitude, although in flow mode different microreactors connected in series were used, making hard an exact comparison.

Different examples of anti-Markovnikov Wacker oxidation of differently functionalized styrenes has been compared in batch and flow conditions. The latter sensibly improved selectivity at quantitative conversion [36]. Styrenes were also synthesized in flow by the same group from different aryl iodides and ethylene [37], as well as unsymmetrical stylbenes [38]. A tube-in-tube reactor configuration was proposed, allowing gas permeation from the shell to the inner pipe, where the liquid reactants are 
flowing. The same reactor configuration was also adopted for the production of thioureas from gaseous ammonia [39] and for the Pd-catalysed carbonilation of aryl and ethyl alogenides with different nucleophiles. A Teflon semipermeable membrane allowed the controlled addition of CO, thus improving selectivity and safety [40]. A tube-in-tube reactor was also used for the idroformylation of styrenes with syngas [41]. The dual concept has been proposed by Gutmann et al. [42], suggesting to shift the equilibrium of aldehydes decarbonilation by removing selectively $\mathrm{CO}$ in a tube-in-tube reactor. The liquid flowed in the annular section, whereas a flow of inert gas in the inner tube allowed the selective abstraction of $\mathrm{CO}$ from the reacting mixture (Fig. 2).

The synthesis $\alpha$-halo ketones as building blocks for HIV protease inhibitors has been proposed in a tube-in-tube system. Diazomethane has been produced in situ in the inner tube and progressively dosed in the shell thanks to a semipermeable membrane [43].

A multi-channel membrane microreactor was also proposed tested for Knoevenagel condensation of benzaldehyde and ethyl cyanoacetate. The catalyst employed was a Cs-exchanged faujasite $\mathrm{NaX}$ as an example of heterogeneous basic catalyst, improving the system applicability due to catalyst immobilisation. Furthermore, the use of a membrane microreactor allowed the continuous removal of water with consequent better product purity and final yield above the equilibrium conversion in batch mode [44].

Spinning tube-in-tube reactors were also used for the selective oxidation of alcohols to aldehydes. A good control of the exothermicity was allowed, avoiding the need of careful dosing the reactants [45].

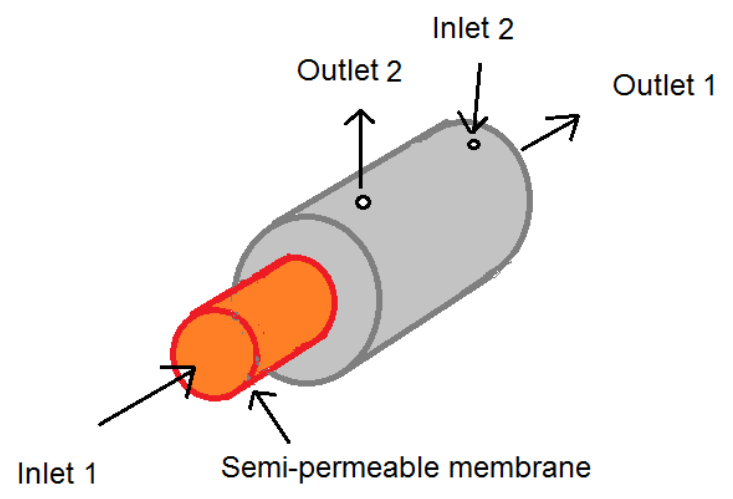

Figure 2. Basic concept of tube-in-tube reactors. In the case of spinning devices, the inner tube rotates with a given angular speed.

Functionalised anilines are important intermediates for the synthesis of active principles, dyes and pigments. Typically, they are obtained by reduction of nitroarenes, though leading to significant selectivity issues and wastes. A suitable alternative can be the selective reduction with noble metal catalysts, but their cost raises limitations in their use. Different reducing agents, besides $\mathrm{H}_{2}$ were also 
proposed, among which hydrazine showed promising due to the formation of $\mathrm{N}_{2}$ as byproduct. Hydrazine was combined with in-situ generated $\mathrm{Fe}_{3} \mathrm{O}_{4}$ nanocrystals in flow conditions [46].

Iron oxide nanoparticles may be used for inductive heating. Examples of magnetic cores surrounded by silica shells were used for flow microreactors heating. Surface Pd functionalization was additionally proposed [47].

Many examples of coupling and cross-coupling reactions have been recently proposed in flow mode (see e.g. [48-56]). Typically, the Pd catalyst is immobilized on a support (e.g. amorphous of mesoporous silica) and packed into the reactor. However, this may limit severely catalyst life, as effectively reviewed by Cantillo and Kappe [57]. Indeed, the catalytic cycle involves the oxidation of $\mathrm{Pd}^{0}$ to $\mathrm{Pd}^{\mathrm{II}}$, which can be readily solubilized and leached in a chromatographic fashion downstream by reactants flow. At the end of the catalytic cycle the metal is regenerated back, so that in batch mode the catalyst is almost unaffected because Pd adsorbs again on the support. By contrast, this progressive leaching and migration leads to the deactivation of the catalyst. Different configurations including a Pd-based precatalysts have been developed [58]. The issue of possible Pd leaching from heterogenised catalysts and its influence on various coupling reactions has been considered by Pagliaro et al. [28]. Microfluidic extraction has been also coupled to cross-coupling [59]. Silica-supported Pd catalysts have been also reviewed for the Heck coupling reactions [60].

An extremely fast carboxylation reaction has been also proposed in flow mode [61]. Taking advantage of the ease of assembly of different units in microreacting systems, multiple mixers and reacting zones allowed optimal product yield.

An applicative example was proposed for the synthesis of Boscalid $^{\circledR}$, an antifungine principle, at first by optimizing the reaction conditions to sufficiently speed up the reaction for application in continuous flow mode [62]. Furthermore, a continuous flow system showed particularly effective and versatile for the synthesis of a new series of chemokine receptor ligands from commercial raw materials [63]. Other examples of newly developed molecules through continuous flow reactors are reviewed by Rodrigues et al. [64].

Many other examples of heterogeneously catalyzed reactions have been recently reviewed by Frost and Mutton [65], Munirathinam et al. [66] and by Kirshning et al. [67]. The synthesis in situ of a porous polymer for the immobilization of covalently bound catalysts has been proposed [68]. Heterogenised Pd-NHC catalysts have been compared under batch and flow conditions, although life tests have not been reported [69]. An oxime-based palladacycle has been immobilized on a poly(vinylpyridine)/glass composite material and formed as Rashig rings to pack a microreactor. Tests have been carried out for cross-coupling reactions [70]. Other supports have been also proposed, such as cross-linked imidazolium-based materials, able to load high amount of metal [71]. Additionally, nanoconfinement of asymmetric catalysts in multiwalled carbon nanotubes was also accomplished [72,73]. Pd supported over 
monoliths has been considered for continuous flow reactions [50,68,74-77]. The comparison of homogeneous and heterogeneous paths for the ligandless Mizoroki-Heck reactions are also overviewed [78]. The role of Pd in coupling reactions has been taken into account by critically assessing the role of the "heterogeneous" vs. "homogeneous" species playing a role in the reaction [79]. The life of heterogeneous Pd catalysts has been also considered by Reynolds et al. [80] demonstrating negligible leaching. The opposite trend was proposed by Richardson et al. [81], who focused on the role of leached $\mathrm{Pd}$ in the catalysis for coupling reactions. The same concept was also addressed by Shore et al. [29], who developed capillaries coated with Pd and heated by MWs for coupling reactions. The role of leached Pd ions in this case seems minimal, as well as for the results reported by Stouten et al. [82,83]. Finally, an overview of the importance of the leaching problem in flow chemistry has been very recently proposed by Hii et al. [84].

Very interesting reports on the immobilization of enantioselective catalysts on solid supports, typically polymers such as polystyrene, are also presented [85].

In case homogeneous catalysts are used, they have to be separated and recycled, especially if Pt-group metals are used. Therefore, appropriate methods for their recycle have to be adapted to flow synthesis, as reviewed by Vural Gürsel et al. [86].

\subsection{Photochemistry and photocatalysis}

Singlet oxygen finds interesting applications for biomedical applications, e.g. as antimicrobial or anticancer agent. Its photoinduced dye-sensitized production has been commonly used on lab scale, but it is scarcely scaled-up due to the need of considerable amounts of organic substances and safety issues. Microreacting systems have been developed which provide oxygen by mass transfer through the reactor walls, without separate oxygen feed. Singlet oxygen is then used as a powerful and sustainable oxidizing agent for different test reactions, e.g. for the synthesis of ascaridole from $\alpha$-terpinene. A fluoropolymer microcapillary reactor has been used, consisting of 10 pipes with $0.1 \mathrm{~mm}$ diameter. No mixing problems have been observed for a one-channel system, but oxygen distribution and mixing was not trivial in the case of multichannel reactors. Oxygen flow was regulated by applying increasing external pressure and it represented the kinetically limiting factor [87].

Continuous flow reactors for photochemical and photocatalytic applications are widely described by Su et al. [88]. Enhancement in selectivity was reported, e.g., for the photochemical rearrangement of 4hydroxycyclobutenones to $5 \mathrm{H}$-furanones. The reaction was unselective in batch mode due to the consistent photodegradation of the product. As well, the scale-up of the continuous photobromination of 5-methylpyrimidine, a precursor of Rosuvastatin was successful, whereas it was substantially unscalable in batch due to overbromination and prolonged reaction time (16-64 h already on millimolar scale). [89]. 
It seems that due to short life time of radical species, photochemistry is well suited to application with microreactors, although basic differences between reaction time and residence time are often confused (see paragraph 3.6) [88]. Examples of batch cyclisation reactions were proposed with much higher yield in continuous mode with respect to batch [90]. In other cases, some synthetic routes have been appealed as too slow in batch mode, therefore abandoned, whereas in continuous mode the applicative possibilities change dramatically. Often, this increased productivity may be ascribed to improved irradiation in microreactors than batch mode when scaled up.

The synthesis of artemisinin, one of the most powerful antimalarial drugs, involves a key photochemical step that typically prevented large-scale production. Lévesque and Seeberger proposed a continuous-flow alternative with $65-70 \%$ overall yield [91]. Another interesting application is the synthesis of intermediate active species such as the Vilsmeier-Haack reagents for the production of anhydrides under mild conditions [92].

A serpentine plate reactor has been developed for the abatement of endocrine disruptive agents from water through UV irradiation [93]. A model for the reactor was proposed, including radiation, kinetics and fluid dynamics.

\subsection{Nanoparticles synthesis}

Although solid materials are far from the typical examples of application of microreactors and flow chemistry, some interesting examples can be considered in this field.

Silver nanoparticles ( $c a .4 \mathrm{~nm}$ in size) have been prepared through a MW assisted device coupled with a flow microreactor [94]. In order to obtain dimensionally homogeneous nanoparticles very efficient mixing of the precursors solutions is needed and was achieved through collisional mixing in a microchannel device. This was coupled with MW heating, which avoids the deposition of a silver coating, obtained in the case of traditional external heating. The mixing and heating zones are separated and designed in spiral form. Spinning disk devices are also used for the surface preparation of silicon wafers [95].

Mixed oxides are often used as ceramic materials for various applications, as semiconductors and as catalysts. Especially in the latter case, considerable improvement of reactivity is achieved thanks to nanostructuring. This is hardly achievable through traditional synthesis routes, which involve high temperature treatments to impart the desired phase purity and crystallinity. Furthermore, this is a batch multistep process and it is quite impossible to limit the residence time at high temperature to achieve satisfactory nanostructuring coupled with sufficient thermal resistance. The same holds when the quenching of solid phases is needed to achieve non thermodynamically favoured crystal phases. A continuous flow synthesis has been developed in the last decades, namely flame pyrolysis, which allows the one-pot synthesis of single or mixed oxides nanoparticles. An organic solution of the precursors is 
fed to a burner together with a flow of oxygen. By calibrating the residence time into the flame and the combustion enthalpy of the solvent, the particle size and, more in general, catalyst properties such as thermal resistance, can be finely tuned [96-101].

Mesoporous silica was synthesized in flow by means of a microreactor. Very short time was needed for the synthesis, satisfactory yield (ca. 60\%) and material properties were obtained with respect to batch mode. The prepared material, added with iron oxide nanoparticles and functionalized with amines was used as catalyst for the Knoevenagel condensation of benzaldehyde with ethyl cyanoacetate, ethyl acetoacetate and diethyl malonate. The recyclability was ensured by the magnetic character imparted by iron oxides, whereas reactivity was tuned by steric hindrance of the amine [102]. The versatility and control of micromixers also allowed to tune particle size over one order of magnitude and shape (dense or hollow spheres) during the synthesis of mesoporous silica [103]. Also in this case residence time was very short (5-9 $\mathrm{min}$ ) and materials properties have been modified by varying the hydrolysis conditions of the silica precursor and the flow regime across the microreactor.

\section{Reaction and reactor engineering}

\subsection{Transport phenomena}

One of the most claimed advantages of micro- and continuous flow reactors is the enhanced heat and mass transfer. Typically, such transport properties are quantified by the liminar coefficient $(h)$ and by the mass transfer coefficient $\left(k_{c}\right)$. These parameters are in turn determined on the basis of empirical correlations between adimensional numbers. Therefore, it is essential to get reliable experimental data to correctly represent the fluid dynamics of the system. Furthermore, depending on fluid flow and reactor geometry, more or less significant pressure drop may arise, to be quantified through proper models.

Efficient heat transfer is one of the key drivers for the development of innovative fluent systems. In particular, heat exchangers/reactors are promising systems due to improved safety and selectivity control. Fluid flow has been studied as function of channels geometry [104]. By tuning channels configuration one may achieve the formation of vortices, called Dean vortices, due to flow instability even at relatively low values of the Reynolds number $(R e)$. This occurs above a critical value of the Dean number $(D e)$, defined as

$$
\begin{aligned}
& D e=R e \sqrt{\frac{d_{h}}{R_{c}}} \\
& R e=\frac{\rho u d_{h}}{\mu}
\end{aligned}
$$


Where $\rho$ is the density and $\mu$ the viscosity of the fluid, $u$ the velocity, $d_{h}$ channel diameter and $R_{c}$ the curvature radius. This turbulence induced by channel's curvature is beneficial from the point of view of mixing and, thus, of transport properties. Re represents the ratio between inertia and viscous forces and typically ranges below 2000 for strictly laminar conditions and above 3000 for completely turbulent flow. Widely different values occur in flow chemistry reports, sometimes well below 10, with consequences on transport properties.

A summary of the adimensional numbers and the relative correlations applied to microreactors has been effectively proposed by Kockmann et al. [105,106]. In the same papers the reader can find the typical ranges of adimensional groups found for these applications, of course depending on geometry and design.

Very interesting correlations for plate-type corrugated channel reactors are proposed [104]. The Darcy coefficient is reported versus $R e$ and predicts (as expected) higher pressure drop for more corrugated geometries. The pressure drop in corrugated channels is due to the distributed energy loss in the straight portion of the channel, plus the localized loss due to the bending of the channel and an additional contribution due to the propagation of the vortices downstream each bend. Hence, pressure drop is correlated to the length of the straight lines. When increasing the length, the number of bends lowered and this reduced the pressure drop. However, if the length is lower than the vortex propagation length, the elongation of the straight line favours vortex propagation and, so, the pressure drop increases. In addition, the overall heat transfer coefficient $(U)$ and $h$ are calculated proposing a correlation between the Nusselt number $(\mathrm{Nu})$ and $R e$, with

$$
\begin{aligned}
& N u=\frac{h d_{h}}{k} \\
& \frac{1}{U A}=\frac{1}{h_{e} A_{e}}+\frac{y}{k}+\frac{1}{h_{i} A_{i}}
\end{aligned}
$$

where $\mathrm{k}$ is the thermal conductivity of the fluid [104] and the subscripts $e$ and $i$ define the two sides across the wall where heat transfer takes place. $U$ normally ranges between 500 and $5000 \mathrm{~W} / \mathrm{m}^{2} \mathrm{~K}$ depending on material, employed fluids, temperature and channel geometry [105]. Mixing time is also compared for different geometries, calculating the radial mixing and plug flow approximation as number of equivalent CSTR (Continuous Stirred Tank Reactor) reactors.

The development of robust models to compute the transport properties for these novel reactors configurations is an incoming challenge. An example is reported by Masters et al. [107], reporting the case of a microchannel plasma reactor. Significant deviations from conventional models for straight 
channels have been observed. Complex geometries are often proposed, therefore novel empirical correlations have to be drawn and this is an incoming engineering challenge.

Models are also required to effectively describe mixing in these devices, which is one of the most straightforward features, but also one of the hardest to scale-up. Most microreacting systems are operated at relatively low Re values, i.e. under laminar regime. The absence of turbulence determines radial mixing by diffusion, only. The comparison between the rates of reaction and mass transport is conveniently expressed by the Damköhler number:

$$
D a=\frac{\text { Rate of reaction }}{\text { Rate of mass transport }}
$$

Of course its expression depends on the type and order of the reaction, thus its quantification depends on the reaction kinetics. The Fourier number $(F o)$ is also useful, representing the ratio between the residence time and the transverse diffusion time:

$$
F O=\frac{4 D \tau}{d_{h}^{2}}
$$

where $D$ is the diffusion coefficient and $\tau$ is the residence time. Nagy et al. [108] also used a parameter $\chi$, dependent on kinetics and feed ratio, that leads to the following definition of $D a$ :

$D a=\frac{\chi}{F o}$

After building the graph reported in Fig. 4, the authors indicate the zones above the curves as warrant of mixing aids. Indeed, if $D a$ is higher than one the reactivity of the system is faster than diffusion rate. In this condition concentration gradients may negatively affect the reaction rate. Therefore, mixing aids, or cold premixing before entering the reaction zone are suggested. 


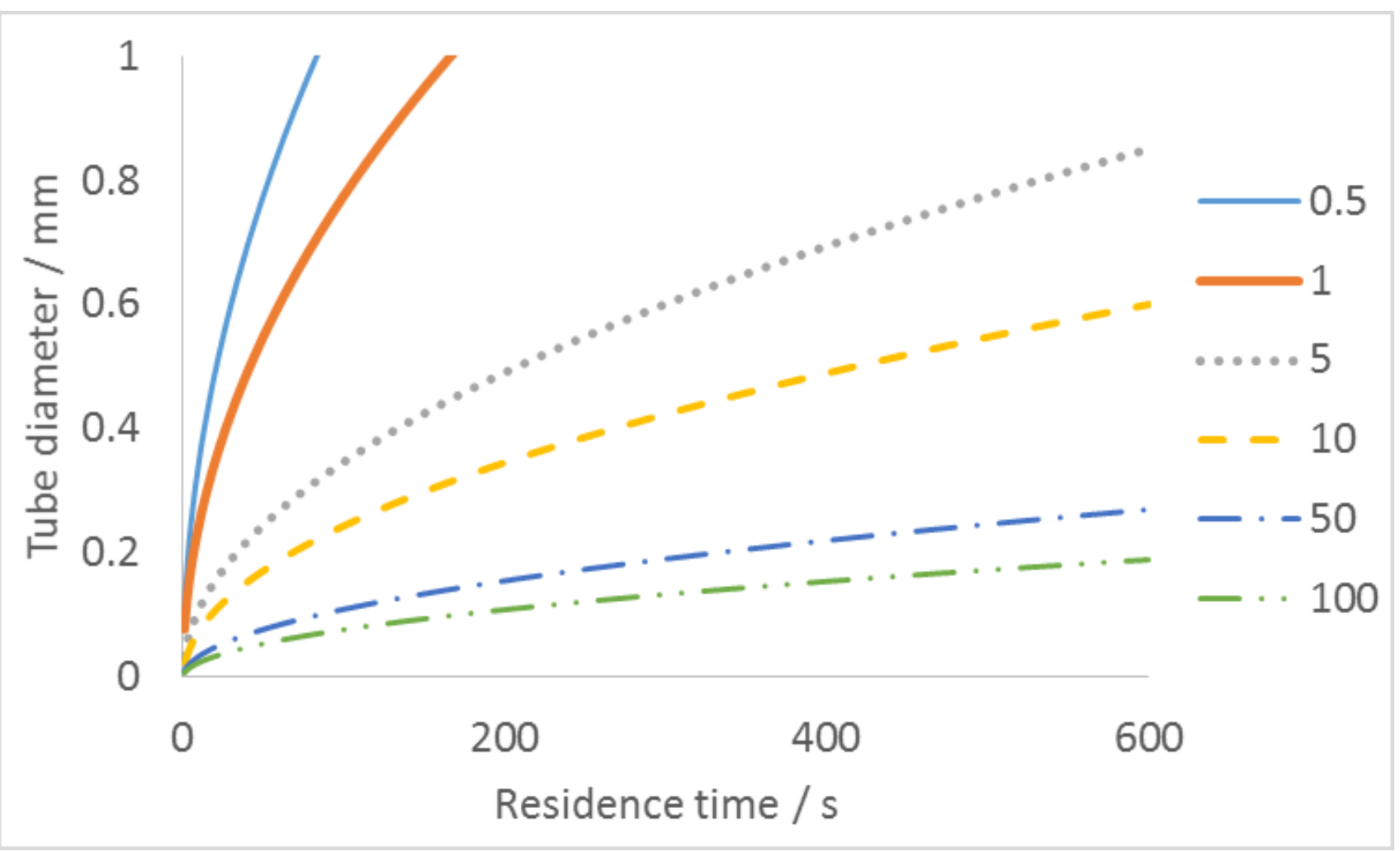

Figure 4. Curves corresponding to $D a=1$ for different values of $\chi$ (reported in the legend). Combinations of tube diameters and residence times falling above $D a=1$ represent reactor size and flow conditions requiring the use of mixing units [108].

Different models are also presented to describe the flow regime [108], together with the guidelines for their choice, as reported in Table 1.

Table 1. Critical values of $F o$ and $\chi$ to evaluate the impact on the flow profile along the reactor [108].

\begin{tabular}{|l|c|l|l|}
\hline \multicolumn{2}{|c|}{ Fo, tubes } & \multicolumn{1}{|c|}{ Fo, square section } & \multicolumn{1}{|c|}{ Notes } \\
\hline \multicolumn{2}{|c|}{$<0.16$} & Laminar flow reactor model \\
\hline$<2.1$ & $<3.3$ & Large deviations from plug flow \\
\hline$<21$ & $<33$ & Small deviations from plug flow \\
\hline$>21$ & $>33$ & Plug flow behavior \\
\hline \multicolumn{2}{|r|}{$\chi<$ Fo } & No need of premixing \\
\hline \multicolumn{2}{|r|}{$\chi>$ Fo } & Premixing needed \\
\hline
\end{tabular}


Liquid-liquid mixing has been experimentally tested by Plouffe et al. [109] to determine a suitable correlation for the mass transfer coefficient. Different solvent couples, microreactors and micromixers have been tested. The preferred condition to favour mass transfer would be an intimate contact between the two immiscible phases as a sort of emulsion. However, this can be achieved at very high flowrate, which is not compatible with the residence time window of these devices. More conventional situations are parallel flow, where mass transfer is only based on lateral diffusion, and slug flow, where the recirculatory motion reduces the thickness of the boundary layer at the interface improving mass transfer. Different micromixers designs are presented, with their flow patterns and their effectiveness for a fast, diffusion-limited reaction. The most effective mixers allow to completely break the flow. When slug flow is active, an increase of flowrate decreased conversion due to lower residence time, which prevailed over the increased interface area or recirculation. The same was observed also after the transition to parallel flow. Dispersed flow was achieved with complex geometry, only. On the other hand, the use of simple $T$ mixers can be hard to scale-up, working typically in slug or parallel flow regime. Some design strategies have been proposed (see e.g. Wang et al. [110]) to overcome this issue, as better discussed in paragraph 3.3.

Heat and mass transport are usually neglected in studies about photochemical and photocatalytic topics. This is usually due to the chemistry-based explorative nature of most of these reports. To overcome mass transport limitations in photochemical transformations, several novel types of reactors, such as spinning-disc reactors, monolithic reactors, thin-film reactors, and microreactors have been developed [88].

Micromixers are conventionally coupled to microreactors when very efficient mass transfer should be reached. An example is reported, where the highest reported $R e$ has been achieved (ca. 4400). This was successfully applied to the emulsification of silicone oil in water under turbulent conditions [111].

Different examples of mixing are visually reported by Hartman et al. [112], whereas Holvey et al. [113] proposed different mixers geometries and analysed their influence on pressure drop, almost fully localized in the mixing zone, and reactivity.

Phase mixing is even more important in the case of tri-phase systems, such as heterogeneously catalyzed hydrogenation reactions. A review on the topic has been proposed by Irfan et al. [114], showing the advantage of flow chemistry in this field.

Different types of micromixers have been reviewed by Nguyen et al. [115] and the relative modeling of flow patterns has been proposed by various authors [115-117], together with the summary of the relevant adimensional numbers and simulation techniques. Examples of micromixing schemes are sketched in Figure 5. 

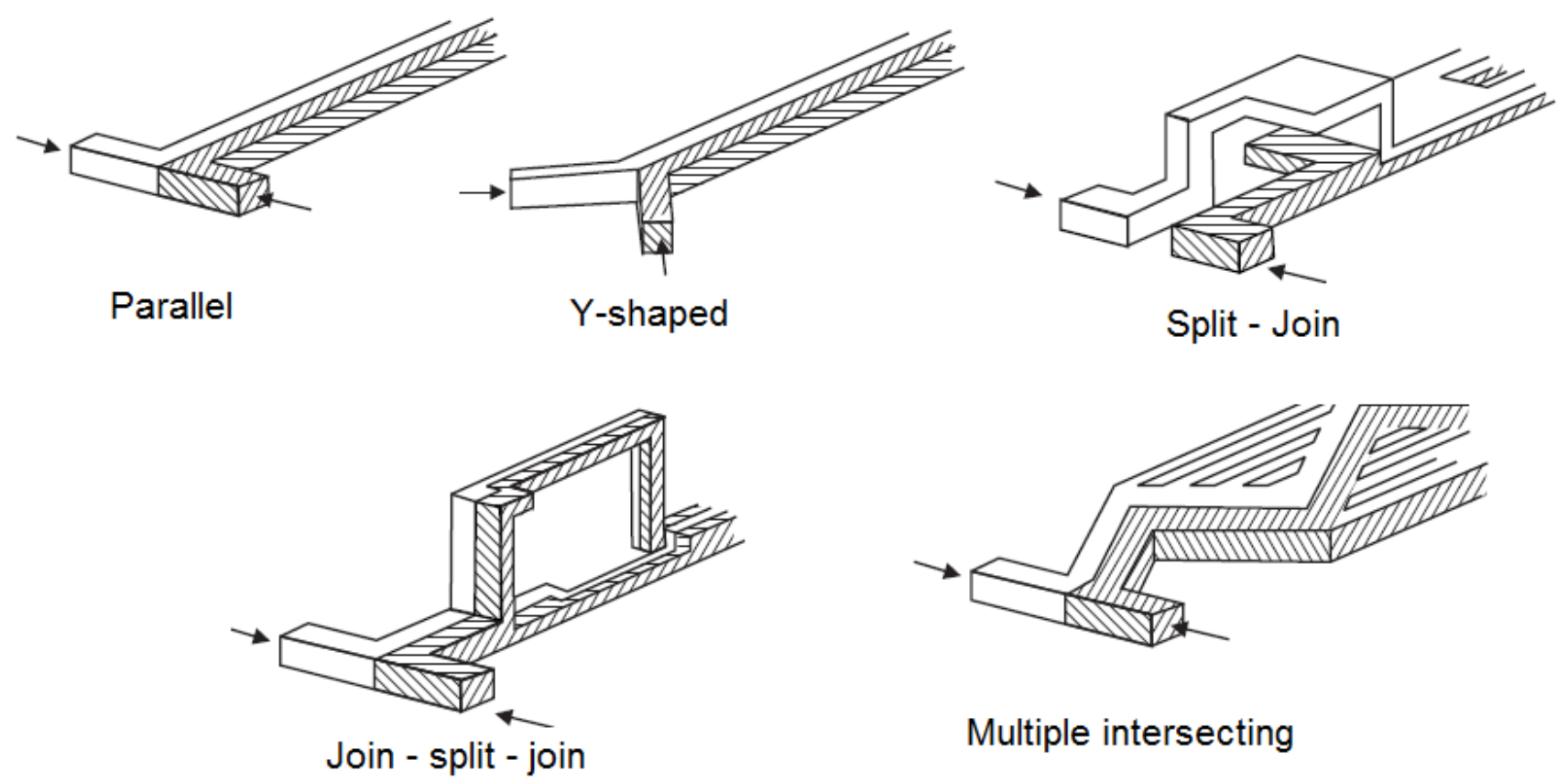

Multiple intersecting

Figure 5. Examples of micromixers leading to various flow patterns. Readapted from [115]

An example of proteolysis mediated by pepsine well represents the importance of mass transfer and efficient mixing [118]. It appears that only the enzymes near the interface between the two reacting fluids can react with hemoglobin molecules due to the mass-transfer resistance of pepsin and hemoglobin. The other enzyme molecules located in the "enzyme compartment" react only with some produced peptides coming from the interface, but they are unable to react with the initial hemoglobin substrate. Thus, substrate molecules located close to the interface are rapidly and completely digested by pepsin whereas substrate molecules away from the interface are not hydrolised. As a result, using a microfluidic reactor peptides with an intermediate length are much less than in batch mode, small peptides prevailing and leading to overall higher hemoglobin conversion.

Copper flow reactors were applied to many different reactions thanks to the valuable heat exchange properties [119]. Examples are 1,3-dipolar cycloadditions, macrocyclizations, Sonogashira coupling, Ullmann-type reactions and decarboxylations.

The most important engineering aspects associated with flow chemistry have been very recently reviewed [120], including mass-, heat- and photon-transport, intrinsic kinetics, automation of chemical processes and solids handling.

\subsection{Reactor design}

A toolbox for the selection of the most appropriate reactor configuration has been proposed by Plouffe et al. [121]. Reactions are divided in different types depending on kinetics (A, B, C), contacting phases 
(homogeneous, liquid-liquid, gas-liquid and liquid-solid) and the reaction network (parallel and consecutive reactions). Different continuous reactor configurations are proposed and compared based on some case histories, namely plate, coil and CSTR. Multi-injection systems also allowed to limit the heat generation for strongly exothermal reactions.

A prototype of microreactor has been developed for the small-scale evaluation of synthetic enzyme pathways. The model reaction is based on $\beta$-galactosidase, glucose oxidase and horseradish peroxidase, a three step enzyme pathway that does not occur in nature [122]. Two different reactor configurations have been compared: a packed bed composed of microbeads coated with the three different enzimes and a coated channel configuration. With respect to the multi enzyme bead packed bed, the coating was 3fold more productive, but compared on an enzyme mass basis, it overperformed by more than one order of magnitude. A simple deterministic model based on the Michelis-Menten kinetic model has been also developed.

Micro- and milliliter-scale reactors are commercialized with different modular solutions. However, in order to fully exploit the advantages of the technology for a given reaction, some specific tools have to be optimized/adapted, e.g. the mixing or heat exchange zone. This may imply unconventional design, which is hard to reproduce or scale-up. In this view, it is possible to exploit the potential of 3D printing or additive manufacturing (AM), to achieve on demand configuration of the microreactor with minimum efforts, almost nil waste and relatively inexpensive materials. The idea is intriguing because it allows the construction of tailored reactors, but the main issues are based on the available materials for manufacturing and on the spatial resolution achievable. Glass has good inertness and transparency, it would be suitable on lab scale, but its AM application is in explorative stage, only. Five common AM techniques have been considered for millilitre-scale reactor fabrication: stereolithography, multi-jet modelling, selective laser melting, selective laser sintering and fused deposition modelling [123].

Extrusion-based techniques are relatively inexpensive and make use of a viscous molten thermoplastic polymer in a layer-by-layer process. A number of inert materials are available for the scope: acrylonitrile butadiene styrene (ABS), polycarbonate (PC), polycarbonate-acrylonitrile butadiene styrene (PC-ABS) and polyetherimides (ULTEM). This technique has been used to compose a split and recombine static mixer. Problems may arise due to the spatial resolution, which may induce leaks if the produced tube wall is not fully dense.

Stereolithography is based on the layer-by-layer photopolymerisation of a liquid resin. The materials available are limited to UV-curable polymers, i.e. acrylates, epoxides and urethanes. It offers good resolution and sub-millimiter pipe design, enabling the production of complex or narrow geometries, but some mechanical properties of the resins may not be optimal. Some swelling may also occur with particular solvents. Another keypoint is the thermal resistance up to $150^{\circ} \mathrm{C}$ only, with some softening already at $50^{\circ} \mathrm{C}$. A system of this type was used for the continuous flow oxidation of different aldehydes 
to methylesters, which was already showed as conveniently carried out in flow-mode with respect to batch [124]. Some additional advantages of the AM configured reactor with respect to a simple coil have been shown in most cases [123], even if the reaction conditions for testing are not fully specified to allow a rigorous comparison.

A different approach is used during laser sintering, which starts from powder materials and is able to achieve satisfactory or not spatial resolution depending on laser spot and powder size. In most cases, unacceptable porosity of the manufactured reactor causes leakage under pressure. An interesting alternative is the selective laser melting, which enables the production of metallic reactors. In this case melting usually ensure the formation of dense parts. The most applied material is AISI316 stainless steel [125], but examples are found also with aluminum [126] or titanium. The advantages and disadvantages of the different AM techniques have been effectively compared by Capel et al. [123] as synthesized in Table 2.

Table 2. Critical comparison of the AM techniques available for the manufacturing of tailored reactors [123].

\begin{tabular}{|c|c|c|c|c|c|}
\hline AM technique & Materials & $\begin{array}{l}\text { Chemical } \\
\text { stability }\end{array}$ & $\begin{array}{l}\text { Thermal } \\
\text { stability }\end{array}$ & $\begin{array}{l}\text { Engineering } \\
\text { \& design } \\
\text { limitations }\end{array}$ & Resolution \\
\hline $\begin{array}{l}\text { Fused Deposition } \\
\text { Modelling }\end{array}$ & Thermoplastics & $\begin{array}{l}\text { Variable; } \\
\text { chemical } \\
\text { degradation } \\
\text { for } \\
\text { polyesthers }\end{array}$ & Variable & $\begin{array}{l}\text { Removal of } \\
\text { internal parts } \\
\text { may be } \\
\text { difficult for } \\
\text { complex } \\
\text { geometries; } \\
\text { external is } \\
\text { simple. }\end{array}$ & $\begin{array}{l}\operatorname{Max} \pm 0.3 \\
\operatorname{mm}\end{array}$ \\
\hline Laser Sintering & $\begin{array}{l}\text { Polymers (e.g. } \\
\text { Nylon, PP) and } \\
\text { ceramics in } \\
\text { experimental } \\
\text { stage }\end{array}$ & $\begin{array}{l}\text { Amides may } \\
\text { be attacked } \\
\text { by } \\
\text { nucleophiles } \\
\text { and strong } \\
\text { bases }\end{array}$ & Variable & $\begin{array}{l}\text { Complex } \\
\text { removal of } \\
\text { unsintered } \\
\text { parts }\end{array}$ & $\begin{array}{l}\operatorname{Max} \pm 0.2 \\
\mathrm{~mm}\end{array}$ \\
\hline Stereolithography & $\begin{array}{l}\text { UV curable } \\
\text { polymers }\end{array}$ & Poor & $\begin{array}{l}\text { Generally } \\
\text { poor }\end{array}$ & $\begin{array}{l}\text { Easy clean up } \\
\text { of uncured } \\
\text { resin }\end{array}$ & $\begin{array}{l}\text { Excellent, } \\
\pm 0.1 \mathrm{~mm}\end{array}$ \\
\hline
\end{tabular}




\begin{tabular}{|c|c|c|c|c|c|}
\hline $\begin{array}{l}\text { Selective Laser } \\
\text { Melting }\end{array}$ & Metals & High & Very high & $\begin{array}{l}\text { Removal of } \\
\text { support } \\
\text { structures } \\
\text { may be } \\
\text { difficult; } \\
\text { polish } \\
\text { sometimes } \\
\text { needed to } \\
\text { improve } \\
\text { surface } \\
\text { smoothness }\end{array}$ & $\begin{array}{l}\text { Excellent, } \\
\pm 0.1 \mathrm{~mm}\end{array}$ \\
\hline $\begin{array}{l}\text { Multi-jet } \\
\text { Modelling }\end{array}$ & $\begin{array}{l}\text { UV curable } \\
\text { polymers }\end{array}$ & Poor & $\begin{array}{l}\text { Generally } \\
\text { poor }\end{array}$ & $\begin{array}{l}\text { Easy clean up } \\
\text { of uncured } \\
\text { resin }\end{array}$ & $\begin{array}{l}\text { Excellent, } \\
< \pm 0.1 \mathrm{~mm}\end{array}$ \\
\hline
\end{tabular}

MW-assisted reactors are reviewed with microreactors as process intensification tools [127]. The FlowSynth system [128] allows temperatures of up to $230^{\circ} \mathrm{C}$ and pressures of up to 30 bar with flow rates between 10 and $200 \mathrm{~mL} / \mathrm{min}$. It can produce many $\mathrm{kg}$ of product per day. It showed interesting applications for the Heck reaction in a continuous flow system as a mean to improve productivity through MW, scarcely scalable in batch due to the poor penetration capacity of MW (5 cm in most solvents). MW and ultrasound (US) assisted synthesis in continuous flow have been also proposed in the biorefinery field up to the pilot and industrial scale [127,129].

Proper reactor design and its modeling are challenging tasks for the design and development of photoreactors. In addition to the momentum, mass and energy balances, one should also consider the selection of suitable light sources, the emission, transport and absorption of photons and the geometry and position sources and targets. Additional complexity is encountered when the concentration fields of radiation-absorbing species are not uniform in photoreactors $[88,130]$. Compatibility aspects of the reactor with the light sources and solvents should be taken into consideration when designing an efficient photochemical process. The use of transparent materials is crucial to fabricate suitable photoreactors, which is not a trivial task, especially when working under unconventional conditions (e.g. under high pressure) [131,132]. The reactor material should allow for efficient photon transport from the light source to the reaction medium. In addition, the geometries of photoreactors and reflectors need to be optimized. Often, a cooling system has to be integrated to control the reaction temperature and avoid superheating of the light source. Further, the solvent should be compatible with the chosen light source and the reactor material [88]. 
Typically, the light source is constituted by a medium pressure Hg lamp outside the reactor. However the recent availability of LED sources allowed the direct integration into continuous flow microreactors with optimized emission wavelength tuned with the absorption maximum of the photocatalyst or sensitizer. LED are also characterized by low power input, high-energy efficiency, small size and low cost. Different materials may be used for the reactor, depending on the transparency needs, such as quartz (> $170 \mathrm{~nm}$ ), Pyrex (> $275 \mathrm{~nm}$ ), Corex (> $260 \mathrm{~nm}$ ) and Vycor (> $220 \mathrm{~nm})$. A variety of polymer materials were also tested, such as polymethyl-methacrylate (PMMA), polydimethylsiloxane (PDMS), perfluoroalkoxyalkane (PFA) and fluorinated ethylene propylene (FEP), offering the advantage of high light transmission, easy fabrication, and low cost. Caution should be put on swelling in some organic solvents.

Conversion is dependent on the efficiency of photon transport. Indeed, irradiation inhomogeneity and the corresponding variations in reaction conditions can reduce yield and selectivity [88]. Usually, microreactors are characterized by higher quantum yield due to shortened optical path and better homogeneity of the radiation.

A new synthetic route for doxercalciferol (1a-hydroxyvitamin D2) was proposed by carrying out a photoisomerisation with 9-acetylanthracene as photocatalyst. A capillary (1.59 mm ID, $15.24 \mathrm{~m}$ length) was coiled around a cooled immersion well with a pyrex sleeve. A $450 \mathrm{~W}$ mercury vapor lamp was used. A design of experiments methodology (DoE) was used to optimize the operating parameters $[88,133]$.

Spinning disk reactors were tested, where the contact time was inversely proportional to the angular velocity, for the selective isomerization of $\alpha$-pinene [134]. This technology was considered able of a 8 ton/year productivity of epoxynitrile [135]. A spinning tube-in-tube reactor was also proposed [45] with improved mixing and controlled residence time, leading to minimization of byproducts. Many examples are reported by Anderson [21] indicating improved yield by using continuous vs. batch systems, also in case of MW, ultrasound or photoassisted processes, where the distance from the emitting source is detrimental for reactivity.

A Computational Fluid Dynamic (CFD) model for oligonucleotide synthesis in packed bed columns was used. The kinetic model was developed from small stirred vessels [20]. The effect of pressure drop, reactor geometry and inhomogeneity caused by swelling effects in the packed bed were taken into account.

Selectivity can be effectively tuned by operating a rigorous temperature control. A specially designed reactor has been developed by Corning SAS on demand of Lonza Ltd. to carry out an organometallic mediated reaction in continuous flow with productivity of the order of 2 ton/month [22]. Feed splitting has been optimized for this application. A microstructured manifold has been developed and associated to a serpentine reacting zone and a coupled heat exchange layer. The pressure drop was also optimized. A few $\mathrm{mL}$ volume was obtained with the continuous flow system, to be compared with $1 \mathrm{~m}^{3}$ of the rival batch system. A considerable heat exchange intensification was achieved, by a factor $1.65 \mathrm{MW} \mathrm{m}^{3} / \mathrm{K}$. 
The mixing efficiency was also determined both experimentally and through CFD simulation. The pressure drop was limited to 3 bar during testing with water under experimentally relevant conditions.

Finally, a MW assisted microreactor for organic synthesis is described by Somerville et al. [136] and some examples of commercial integrated microreacting systems have been recently reviewed [137].

\subsection{Scale-up issues}

Scalability is not a trivial issue because the typical similitude laws which hold for more conventional systems should be carefully checked and revised. This is one of the most challenging topics in this field.

Scale-up has been effectively considered by Roberge et al. [3]. Efforts have been undertaken to scaleup microreacting systems for commercial purposes. The first attempts consisted in coupling a number of units, better defined as numbering up. Subsequently, a plate geometry was proposed, allowing the incorporation of different functions in a single plate reactor, including heat exchange and mixing. Examples of compact reactors are proposed, as developed by Lonza and Corning. Different ideas have been proposed, such as modular prototypes, multi-injection systems to cope with exothermal systems, or a precise design of the reactor's inlet channel. This allows a thin tube for the initial stages of reaction, to better control the heat release, followed by pipe enlargement when heat release control is less demanding, to limit the pressure drop. Furthermore, the different reactor plates, made of stainless steel, are thermally coupled with aluminum plates holding the heating/cooling fluid, in order to enhance heat transport [1].

Table 3. Type of reactor and orders of magnitude of reactants flow and productivity [3]. A6-A4 refer to increasing size (as for paper).

\begin{tabular}{|c|c|c|}
\hline Type of reactor & Reactant's flow $(\mathrm{ml} / \mathrm{min})$ & $\begin{array}{c}\text { Productivity per campaign } \\
(\mathrm{kg})\end{array}$ \\
\hline Lab plate & $1-10$ & Grams \\
\hline A6 & $50-150$ & $0.1-300$ \\
\hline A5 & $100-300$ & $\mathbf{3 0 0}-900$ \\
\hline A4 & $200-600$ & $\mathbf{9 0 0}-2500$ \\
\hline
\end{tabular}

Scale-up issues are different for the different reaction classes. When a plate system is adopted area and volume increase by a factor of some units. However, the internal of the system should be kept microstructured for class 1) reactions, to continue ensuring mixing and thermal exchange. This is not the case for class 2) reactions, for which it is better to keep constant the volume/area ratio. For viscous 
systems pressure drop in the mixing zone dominates the scale-up procedure. Thus, flow rate is proportionally increased with the channels size in order to keep wasted energy rather constant.

Examples of scale-up philosophy for different pre-clinical trials for the development of drugs have been summarized [3].

Another example of scale-up of a continuous flow microreactor has been reported for a two-step Li$\mathrm{H}$ exchange and coupling reaction [1]. The first step is a reaction of class 1) with a considerable adiabatic temperature rise, while the second is class 2) without particular needs for heating and mixing. A single channel design, with rectangular shape, with no flow partialisation has been selected as most appropriate for simpler scale-up. The key adimensional numbers and appropriate correlations are reported by Kochmann et al. [1], to compute pressure drop (mainly accounted for in the mixing zone), heat and mass transfer coefficients. The comparison between the reaction carried out in different tools and with reactors of different size is reported in Table 4. It is clear that static mixers and glass microreactors are not useful for this purpose due to inefficient heat transport. With the Lonza A5 microreactor it is possible to achieve optimal temperature control, with reasonable pressure drop, maximizing the product yield. This is important when coupled with the high flow rates, which ensure very high productivity. This system was used for a pilot campaign, leading to $700 \mathrm{~kg}$ of isolated product, and subsequently a 2 ton campaign.

Table 4. Comparison of different reactors for a lithiation reaction [1]. The Lonza reactors adopt the conventional size descriptors as paper sheets.

\begin{tabular}{|c|c|c|c|c|}
\hline Type of reactor & $\begin{array}{l}\text { Mass flowrate } \\
\qquad(\mathrm{g} / \mathrm{m})\end{array}$ & $\mathbf{T}_{\text {out }}\left({ }^{\circ} \mathbf{C}\right)$ & $\Delta \mathbf{P}($ bar $)$ & $\begin{array}{c}\text { Isolated product } \\
\text { yield }(\%)\end{array}$ \\
\hline \multirow[t]{2}{*}{ Static mixer $3 / 8^{\prime}$} & 33 & 9 & 0.3 & 88 \\
\hline & 148 & 41 & 1.6 & 84 \\
\hline \multirow[t]{2}{*}{ Glass microreactor $0.5 \mathrm{~mm}$} & 33 & -14 & 0.4 & 86 \\
\hline & 148 & 15 & 3.2 & 88 \\
\hline \multirow[t]{2}{*}{$\begin{array}{l}\text { Lonza microreactor A6 size, } \\
\qquad 0.5 \mathrm{~mm}\end{array}$} & 33 & -22 & 0.9 & 89 \\
\hline & 140 & -16 & 8.8 & 90 \\
\hline $\begin{array}{l}\text { Lonza microreactor A5 size, } \\
\qquad 0.7 \mathrm{~mm}\end{array}$ & 150 & -20 & 3.4 & 90 \\
\hline
\end{tabular}




\begin{tabular}{|c|c|c|c|c|}
\hline \multirow{2}{*}{$\begin{array}{c}\text { Lonza microreactor A5 size, } \\
1 \mathrm{~mm}\end{array}$} & 150 & -21 & 2.0 & 88 \\
\cline { 2 - 5 } & 237 & -16 & 4.5 & 88 \\
\hline
\end{tabular}

Scale-up is often hard for photochemical reactions in batch mode, because in addition to the common heat and mass transport issues, the distribution of photons into large batch reactors is attenuated due to increased optical path. The use of continuous flow microreactors may overcome these limitations [88].

Heterogeneous photocatalysis has been also proposed in continuous flow, but with significant scaleup issues [88]. Typically, scale-up is accomplished by adding microreactors in parallel. However this is not easily sustainable from the economic point of view due to increase of auxiliary equipment. One significant application allowed the production of $2 \mathrm{~kg} /$ day of 10 - hydroxycamptothecine. However, flow distribution was needed to ensure equal distribution in the channels. This was not trivial since different pressure drop across the reactors may significantly change the flow. Another strategy is the increase of flowrate and reactor length, though this imposes the irradiation over longer length and higher pressure drop. A partial solution has been proposed through numbering-up, since the enlargement of the photoreactor depresses light absorption due to the increase of optical path across the solution. Paraller reactor design has been proposed by $\mathrm{Su}$ et al bu connecting up to 8 capillary reactors for the oxidation of thiols to disulphides [138]. However, up to now there is no process design and optimization study applied to photochemical processes.

Scale-up was successful for a capillary microreactor coiled around a quartz cooling jacket in which a 150W medium-pressure Hg lamp was placed for photochemical applications. The reaction was tested over a variety of 19 substrates, which could be converted within 13-50 min residence time affording the production $c a$. $600 \mathrm{~g} /$ day. The purity of the compound was also very high compared to batch [139].

Some basic issues of process design and scale-up, or better numbering up, have been taken into account by Hessel et al. [6].

The scale-up of MW-assisted systems has been also considered and compared with batch mode for Bohlmann-Rahtz cyclodehydration reactions [34]. Furthermore, a monolithic flow reactor was scaled up for the Pd-catalysed Suzuki-Miyaura reaction under MW heating [74].

The conversion of phenol to 2-allylphenol in a two-step microflow apparatus has been proposed for process intensification in Claisen rearrangement with minutes time regimes. After the optimization of each reaction step separately, the integration proposed selectivity problems. Therefore, different solutions for separation were tested and proposed for scale-up. The authors proposed as main cause of selectivity loss the presence of a base and the reactant (allyl bromide) during the Claisen rearrangement. 
Acid/base extraction, ion exchange resin, heterogeneous base and dilution as kinetic approach, were compared as ways to improve the overall yield [140].

Scale-up issues have been taken into account to increase the productivity by 700 times with respect to a spiral shaped microreactor for the oxidation of different substrates [141]. Two types of plate reactors supplied by Corning were used (Low Flow Reactor and Advanced Flow Reactor), characterized by higher throughput and improved mass transport with respect to the spiral-type microreactor. Reoptimisation of the reaction conditions was compulsory to avoid solids precipitation in some cases.

Finally, the advantages of efficient mixing for purposes of process intensification have been kept together by summing scale-up and numbering up approaches [110]. The flow dispersion unit to mix oleum with cyclohexanecarboxylic acid was enlarged by 16 times and ten parallel units were connected. Microsieve pores were kept with the same diameter but multiplied in number. This procedure for "sizingup" the reactor to a 160-times higher capacity maintained the same product yield (decreased by 1-2\% with respect to the lab-scale microreactor).

\subsection{Process modelling}

Process modelling can be efficiently used to assess the feasibility and viability of candidate continuous processes. Minimal investment is required and numerous process options and configurations can be rapidly evaluated and compared. The continuous synthesis and purification of Ibuprofen, as example of Active Pharmaceutical Ingredient (API) has been proposed [2], chosen among a list of APIs for which a continuous flow synthesis has been proposed/validated. The flowsheet is based on three Plug Flow Reactors (PFR) in series and various mixers. Due to partial availability of kinetic data, a predictive tool for the estimation of chemical reactivity was used. Missing thermodynamic data were computed using the group contribution method, including solubilities. The different process sections have been considered, including separation and heat exchange.

The system was designed for the production of $c a .60 \mathrm{~kg}$ of Ibuprofen per year (46 weeks operation), corresponding to almost $10 \mathrm{~g} / \mathrm{h}$. This was achieved with very small PFR reactors and equipment. Reactor volumes were $c a$. 6, 2 and $29 \mathrm{ml}$, respectively. Very small internal diameter $(5 \mathrm{~mm})$ allowed efficient heat transfer, ending in very small heat duty [2].

Microreactors, micro heat exchangers and micromixers are becoming useful tools for process intensification. Modelling of these devices and their implication in energy and materials intensification of the process is effectively described in comprehensive books (see e.g. [142,143]).

As described previously, scale-up and modelling of photo-microreacting systems is still in pioneering stage. Only recently, microreactors have been proposed for kinetic modelling of selected reactions. For instance the 1,3,3-trimethylindolino-6'-nitrobenzopyrylospiran has different colour in the open- and close-ring forms (scheme 3), which interchange can be activated by light absorption with proper 
wavelength. The reaction has been investigated with variable residence time and a kinetic model for this sample reaction has been drawn [144].
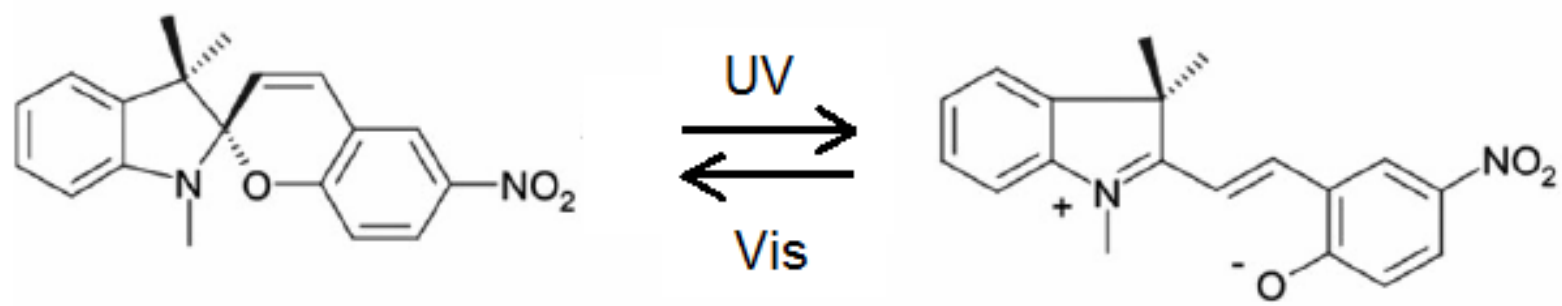

Scheme 3: 1,3,3-trimethylindolino-6'-nitrobenzopyrylospiran: ring opening upon UV light absorption and reverse reaction under visible light or heating.

Furthermore, a photomicroreactor has been specifically designed for kinetic investigations by Su et al. [145]. They considered as model reaction a gas-liquid one, i.e. the aerobic oxidation of thiol to disulphide, including a detailed assessment of mass transfer limitations and the relevant conditions for collecting kinetic data in chemical regime. Accordingly, the propose a kinetic model for the selected reaction.

Process simulation is a particularly hard task for this kind of applications. On one hand, unconventional substances are used, with scarce thermodynamic data available. The latter are required to carry out rigorous mass and heat balances. Furthermore, reactor modelling requires robust kinetic models and parameters, which are available in few cases only. Researchers are therefore strongly encouraged to collect kinetic data and to provide basic knowledge in order to assess the feasibility and launch process development.

\subsection{Safety issues}

Improved safety for continuous flow with respect to batch reactors has been reviewed recently [18].

The typical size and enhanced heat and mass transfer achieved in flow conditions allow to explore unconventional process conditions. For instance, the synthesis of benzimidazole was accomplished at $270^{\circ} \mathrm{C}, 30-50$ bar with extremely short residence time and accordingly scaled [129]. However, the use of high temperatures may lead to safety issues if instable intermediates are involved, such as the case of azides, which rapidly decompose forming nitrogen. In spite of this, the synthesis of triazoles was accomplished at $210^{\circ} \mathrm{C}$ with excellent yield and improved productivity with respect to batch due to 
controlled conditions and residence time under flow [18]. Many different examples of Grignard reactions are summarised by Gutmann et al. [18] as example of very fast and exothermal reactions, which take advantage of the improved heat transfer. As well, many different oxidation processes are reviewed.

Reaction runaway has been considered in case of stopped flow [1]. Heat transfer is tightly connected to the risk of runaway. In the case of exothermal reactions, the heat generated during the reaction should be removed effectively. However, heat transport is much more effective through convective flow, i.e. with moving fluid, than through static conduction. Thus problems may arise in case of stopped flow [1].

The synthesis of trans-2-methylcyclopropanecarboxylic acid was set up through stereoselective cyclopropanation of ethyl crotonate with Corey's Ylide [19]. After the screening and optimisation of reaction conditions, reaction calorimetry and dynamic differential scanning calorimetry (DSC) allowed to assess the safety issues of the reaction, especially aiming at scale-up in flow reactors. Significant safety improvements were achieved due to the absence of hazardous accumulation of the thermally unstable dimethylsulphoxonium methylide.

Hazardous reactants such as phosgene, $\mathrm{HCN}$ and $\mathrm{HN}_{3}$ can be more safely managed in flow regime than in batch, also developing their in-situ synthesis [6]. Examples of organic synthesis under harsh conditions in the pharmaceutical industry, such as nitrations and organometallic reactions, are critically reviewed by Kockmann and Roberge [146].

The exothermicity of some reactions, e.g. the Li- halogen exchange can be kept under control by the use of microreactors. Continuous monitoring of temperature allowed to exclude runaway [147]. Similar concepts were applied by the same authors to a full platform of organic reactions carried out under cryogenic conditions [148]. Finally, an example of Grignard reaction in microreactors confirm that it is possible to effectively control the hot spot [149].

The safety issues connected with liquid phase oxidation reactions have been reviewed recently $[150,151]$. Oxidising reactants typically used are oxygen, ozone or peroxides, which are usually mixed with organic solvents. Possible ignition of explosive reaction mixtures lead to unsustainable increase in temperature and pressure inside the reactor, possibly leading to rupture of the reactor and explosion. To operate safely oxygen partial pressure is decreased by dilution in the pharmaceutical industry, but the recirculation of inert gas increases the process complexity in conventional reactors. The use of microreactors improves the safety of operation because of much more limited mass contained in the reactor, since the power of an explosion is proportional to the cubic root of the explosive mass. Quenching is also provided immediately after microreactors for these applications to avoid any possible flame propagation to the storage tanks.

The efficient removal of metal traces is becoming increasingly important to meet the level of purity requirement for pharmaceuticals. A scavenger-based extraction in flow is described by Vural Gürsel et al. [152] to remove metal catalysts. Liquid-liquid extraction was investigated with slug flow and phase 
separation with a porous fluoropolymer membrane with different scavenger types. Extraction performance as high as $99 \%$ was achieved at $\mathrm{pH} 9.4$ with scavenger/copper of $10 \mathrm{~mol} / \mathrm{mol}$. Process integration was also discussed by coupling this unit downstream to a flow reaction using homogeneous metal-based catalysis, i.e. presenting a continuous uninterrupted metal scavenging unit. The coppercatalyzed azide-alkyne cycloaddition click reaction was studied in one-pot eliminating the need to isolate and handle potentially explosive azide. The triazole product is attained in flow with high yield of up to $92 \%$ with 30 min residence time.

\subsection{Misleading concepts}

From the reported examples, flow chemistry demonstrated an emerging, interesting field in organic synthesis, but many reports, though proposing very good insights in the chemistry of the systems proposed, bring about some confusing concepts and incorrect comparisons.

Very often papers report reaction time as descriptor for continuous microreactors, likely for a direct transposition from a "batch-mode" background. It would be more appropriate to report residence time, that should be calculated for instance as:

$$
\tau=\frac{\text { Reactor volume }}{\text { volumetric flow rate }}
$$

or alternatively as function of catalyst mass in case of catalytic reactions. Under steady state conditions, conversion, selectivity and yield are not expected to increase with reaction time. In order to increase conversion (under identical operating conditions), higher reactor volume should be used, or lower reactants flow. Kinetic equations should be derived accordingly, not as differential equations with respect to reaction time, but with respect to reactor volume (or length, or residence time). Some examples are presented the following.

The synthesis of amines from alcohols, catalyzed by Au has been proposed in flow mode [153]. It seems more appropriately a recirculating/mixing system, rather than a continuous flow reactor. Indeed, the reactor was operated by continuous recirculation of the catalyst, but it cannot be fully addressed as "flow" condition. A time of reaction is indeed introduced, instead of a more appropriate residence time, reactor volume or catalyst mass. Analogously, the kinetic data there reported are defined as concentration vs. time.

Another conventional misleading assumption is that higher reactivity/selectivity is achieved as such in microreactors with respect to batch ones. This may be indeed the observed result, but the conclusion is only partially true if the residence time in flow mode is not compared with the reaction time in batch. 
For instance, Ahmed-Omer et al. [154] compared many different reactions carried out in continuous flow with batch analogues, but the respective operating conditions and the comparison of relevant times are not fully specified. Furthermore, the same authors state that "the combination of continuous flow systems along with heterogeneous catalysis is a relatively new idea...", which may be truely the case for fine organic synthesis, but it is not at all right for most of the typical (and industrially relevant) examples of heterogeneous catalysis, as almost all the refinery processes. Additionally, Hessel et al. [6] compared yield and enantiomeric excess between batch and flow reactors at different times.

The Suzuki cross-coupling reaction has been interestingly reviewed [155], including some emerging applications with microreactors. A continuous flow microreactor was obtained from a monolithic glasspolymer composite [77]. An oxime-based palladacycle was immobilised onto polyvinylpyridine resin and it was loaded in a microreactor containing a monolithic composite material. The apparatus was used in a continuous-flow Suzuki reaction of 4-bromoacetophenone and phenylboronic acid, leading to the coupling product in $84 \%$ yield after $24 \mathrm{~h}$. This concept can be misinterpreted since under continuous flow and in steady state conditions, the same yield is obtained at any time. Furthermore, reutilization is often cited, but it would be more correct to report a steady state diagram for prolonged reaction time, showing that no loss of activity occurred. Comparison of reactivity at widely different residence time/reaction time are also proposed.

The continuous production of active ingredients for artemisin-based antimalarial drugs was compared with batch systems [156]. Multiple $\mathrm{N}_{2} \mathrm{H}_{2}$ feeds improved selectivity and allowed milder reduction conditions with respect to batch processes using $\mathrm{H}_{2}$. Productivity was much higher, although some overlap is present between residence time and reaction time concepts.

Another aspect which is often neglected is that from an industrial point of view it is mostly important to improve selectivity and lifetime rather than conversion (provided it is at least good), because recycle can improve the overall yield, but if high selectivity is reached, low separation costs are ensured.

\section{Conclusions}

Flow chemistry represents an emerging topic, with relevant applications, also in industrial scale, in the pharmaceutical field. Explorative examples are also being developed in photochemistry, photocatalysis, MW-assisted reactions and organic synthesis.

The most important features achievable using microreacting systems are the improved heat and mass transfer. This turns into improved safety and in most cases into higher selectivity and productivity. Much broader operating conditions window may be explored, thus opening the way to reactions unrealizable otherwise. 
Despite these considerable advantages, knowledge is needed from the engineering and scale-up points of view, which should stimulate considerable research in the near future. In general, efforts are needed to use appropriate variables and parameters to describe the reactor performance. Furthermore, correlations are needed to describe heat and mass transfer coefficients and pressure drop depending on the particular geometries and fluid dynamic conditions. As well, detailed kinetic modelling is needed for appropriate reactor design.

In particular, the following actions are needed to cope with the issues which are still open and need to be solved to spread this emerging technology:

1) Borrow the existing and wide knowledge on continuous processes from different sectors of industrial chemistry, of course adapting to the selected scales;

2) Develop appropriate correlations to quantify the relevant transport parameters;

3) Supply relevant thermodynamic and kinetic data, as well as robust estimation tools for unconventional molecular systems;

4) Develop suitable tools for process simulation and cost analysis.

\section{References}

[1] N. Kockmann, M. Gottsponer, D.M. Roberge, Scale-up concept of single-channel microreactors from process development to industrial production, Chem. Eng. J. 167 (2011) 718-726. doi:10.1016/j.cej.2010.08.089.

[2] H.G. Jolliffe, D.I. Gerogiorgis, Process modelling and simulation for continuous pharmaceutical manufacturing of ibuprofen, Chem. Eng. Res. Des. 97 (2015) 175-191. doi:10.1016/j.cherd.2014.12.005.

[3] N. Roberge, D.M.; Gottsponer, M.; Eyholzer, M.; Kockmann, Industrial design, scale-up, and use of microreactors, Chem. Today. 27 (2009) 8-11.

[4] S.G. Newman, K.F. Jensen, The role of flow in green chemistry and engineering, Green Chem. 15 (2013) 1456. doi:10.1039/c3gc40374b.

[5] E. Nicotinate, T. Ouchi, C. Battilocchio, J.M. Hawkins, S. V Ley, Process Intensification for the Continuous Flow Hydrogenation of Ethyl Nicotinate, Org. Process Res. Dev. 18 (2014) 15601566.

[6] V. Hessel, D. Kralisch, N. Kockmann, T. Noël, Q. Wang, Novel process windows for enabling, accelerating, and uplifting flow chemistry, ChemSusChem. 6 (2013) 746-789. doi:10.1002/cssc. 201200766 .

[7] T. Razzaq, T.N. Glasnov, C.O. Kappe, Continuous-Flow microreactor Chemistry under HighTemperature/pressure, European J. Org. Chem. 3 (2009) 1321-1325. doi:10.1002/ejoc.200900077. 
[8] T. Razzaq, T.N. Glasnov, C.O. Kappe, Accessing novel process windows in a hightemperature/pressure capillary flow reactor, Chem. Eng. Technol. 32 (2009) 1702-1716. doi:10.1002/ceat.200900272.

[9] J. Wegner, S. Ceylan, A. Kirschning, Ten key issues in modern flow chemistry., Chem. Commun. (Camb). 47 (2011) 4583-4592. doi:10.1039/c0cc05060a.

[10] J. Wegner, S. Ceylan, A. Kirschning, Flow chemistry - A key enabling technology for (multistep) organic synthesis, Adv. Synth. Catal. 354 (2012) 17-57. doi:10.1002/adsc.201100584.

[11] V. Darvas, F.; Dormán, G.; Hessel, Flow chemistry, De Gruyter Textbook, 2014.

[12] D.. K.N. Hessel, V.; Kralisch, Novel Process Windows: Innovative Gates to Intensified and Sustainable Chemical Processes, Wiley VCH, 2015.

[13] L. Kashid, M.N.; Renken, A.; Kiwi-Minsker, Microstructured Devices for Chemical Processing, Wiley VCH, 2014.

[14] T. Wirth, Microreactors in Organic Chemistry and Catalysis, Wiley VCH, 2013.

[15] D.M. Roberge, An Integrated Approach Combining Reaction Engineering and Design of Experiments for Optimizing Reactions, Org. Process Res. Dev. 8 (2004) 1049-1053. doi:10.1021/op0400160.

[16] D.M. Roberge, B. Zimmermann, F. Rainone, M. Gottsponer, M. Eyholzer, N. Kockmann, Microreactor Technology and Continuous Processes in the Fine Chemical and Pharmaceutical Industry: Is the Revolution Underway?, Org. Process Res. Dev. 12 (2008) 905-910. doi:10.1021/op8001273.

[17] J. Hartwig, J.B. Metternich, N. Nikbin, A. Kirschning, S. V Ley, Continuous flow chemistry: a discovery tool for new chemical reactivity patterns., Org. Biomol. Chem. 12 (2014) 3611-5. doi:10.1039/c4ob00662c.

[18] B. Gutmann, D. Cantillo, C.O. Kappe, Continuous-Flow Technology-A Tool for the Safe Manufacturing of Active Pharmaceutical Ingredients, Angew. Chemie Int. Ed. (2015) 6688-6728. doi:10.1002/anie.201409318.

[19] L. Delhaye, C. Stevens, A. Merschaert, P. Delbeke, W. Briône, U. Tilstam, et al., Development of a Scalable Process for the Synthesis of trans-2-Methylcyclopropanecarboxylic Acid, Org. Process Res. Dev. 11 (2007) 1104-1111.

[20] C. Wolfrum, A. Josten, P. Götz, Optimization and scale-up of oligonucleotide synthesis in packed bed reactors using computational fluid dynamics modeling, Biotechnol. Prog. 30 (2014) 10481056. doi:10.1002/btpr.1966.

[21] N. Anderson, Using continuous processes to increase production, Org. Process Res. Dev. 16 (2012) 852-869. doi:10.1021/op200347k.

[22] P. Barthe, C. Guermeur, O. Lobet, M. Moreno, P. Woehl, D.M. Roberge, et al., Continuous multi- 
injection reactor for multipurpose production - Part I, Chem. Eng. Technol. 31 (2008) 1146-1154. doi:10.1002/ceat.200800132.

[23] D.M. Roberge, N. Bieler, M. Mathier, M. Eyholzer, B. Zimmermann, P. Barthe, et al., Development of an industrial multi-injection microreactor for fast and exothermic reactions - Part II, Chem. Eng. Technol. 31 (2008) 1155-1161. doi:10.1002/ceat.200800131.

[24] http://thalesnano.com/news-and-events/34534, (n.d.).

[25] J.C. Pastre, D.L. Browne, S. V Ley, Flow chemistry syntheses of natural products., Chem. Soc. Rev. 42 (2013) 8849-69. doi:10.1039/c3cs60246j.

[26] M. Asadi, S. Bonke, A. Polyzos, D.W. Lupton, W. Lupton, Fukuyama Reduction and Integrated Thioesterification/Fukuyama Reduction of Thioesters and Acyl Chlorides Using Continuous Flow, ACS Catal. 4 (2014) 2070-2074.

[27] D. Astruc, Palladium Nanoparticles as Efficient Green Homogeneous and Heterogeneous C-C Coumplex Precatalysis: A Unifying View, Inorg. Chem. 76 (2007) 1884.

[28] M. Pagliaro, V. Pandarus, R. Ciriminna, F. Béland, P. DemmaCarà, Heterogeneous versus Homogeneous Palladium Catalysts for Cross-Coupling Reactions, ChemCatChem. 4 (2012) 432 445. doi:10.1002/cctc.201100422.

[29] G. Shore, S. Morin, M.G. Organ, Catalysis in capillaries by Pd thin films using MicrowaveAssisted Continuous-flow Organic Synthesis (MACOS), Angew. Chemie - Int. Ed. 45 (2006) 2761-2766. doi:10.1002/anie.200503600.

[30] P. He, S.J. Haswell, P.D.I. Fletcher, Microwave-assisted Suzuki reactions in a continuous flow capillary reactor, Appl. Catal. A Gen. 274 (2004) 111-114. doi:10.1016/j.apcata.2004.05.042.

[31] I.R. Baxendale, C.M. Griffiths-Jones, S. V. Ley, G.K. Tranmer, Microwave-assisted Suzuki coupling reactions with an encapsulated palladium catalyst for batch and continuous-flow transformations, Chem. - A Eur. J. 12 (2006) 4407-4416. doi:10.1002/chem.200501400.

[32] E. Gjuraj, R. Kongoli, G. Shore, Combination of Flow Reactors with Microwave-Assisted Synthesis: Smart Engineering Concept for Steering Synthetic Chemistry on the "Fast Lane," Chem. Biochem. $\quad$ Eng. $\quad$ Q. $26 \quad$ (2012) 285-307. http://hrcak.srce.hr/index.php?show=clanak\&id_clanak_jezik=129961\&lang=en\npapers3://pub lication/uuid/C22F4292-6AAF-4B5A-BED6-69A009F399F0.

[33] T.N. Glasnov, C.O. Kappe, The microwave-to-flow paradigm: Translating high-temperature batch microwave chemistry to scalable continuous-flow processes, Chem. - A Eur. J. 17 (2011) 11956-11968. doi:10.1002/chem.201102065.

[34] M.C. Bagley, V. Fusillo, R.L. Jenkins, M.C. Lubinu, C. Mason, Continuous flow processing from microreactors to mesoscale: the Bohlmann-Rahtz cyclodehydration reaction., Org. Biomol. Chem. 8 (2010) 2245-2251. doi:10.1039/B926387J. 
[35] B. Gutmann, M. Gottsponer, P. Elsner, D. Cantillo, D.M. Roberge, C.O. Kappe, On the Fischer Indole Synthesis of 7 - Ethyltryptophol $\square$ Mechanistic and Process Intensi fi cation Studies under Continuous Flow Conditions, Org. Process Res. Dev. 17 (2013) 294-302.

[36] S.L. Bourne, S. V. Ley, A continuous flow solution to achieving efficient aerobic antiMarkovnikov Wacker oxidation, Adv. Synth. Catal. 355 (2013) 1905-1910. doi:10.1002/adsc.201300278.

[37] S.L. Bourne, P. Koos, M. Obrien, B. Martin, B. Schenkel, I.R. Baxendale, et al., The continuousflow synthesis of styrenes using ethylene in a palladium-catalysed heck cross-coupling reaction, Synlett. (2011) 2643-2647. doi:10.1055/s-0031-1289291.

[38] S.L. Bourne, M. O’Brien, S. Kasinathan, P. Koos, P. Tolstoy, D.X. Hu, et al., Flow Chemistry Syntheses of Styrenes, Unsymmetrical Stilbenes and Branched Aldehydes, ChemCatChem. 5 (2013) 159-172. doi:10.1002/cctc.201200778.

[39] D. Browne, M. O’Brien, P. Koos, P.B. Cranwell, A. Polyzos, S. V. Ley, Continuous-flow processing of gaseous ammonia using a Teflon AF-2400 tube-in-tube reactor: Synthesis of thioureas and in-line titrations, Synlett. 23 (2012) 1402-1406. doi:10.1055/s-0031-1290963.

[40] U. Gross, P. Koos, M. O’Brien, A. Polyzos, S. V. Ley, A General Continuous Flow Method for Palladium Catalysed Carbonylation Reactions Using Single and Multiple Tube-in-Tube GasLiquid Microreactors, European J. Org. Chem. 2014 (2014) 6418-6430. doi:10.1002/ejoc.201402804.

[41] S. Kasinathan, S.L. Bourne, P. Tolstoy, P. Koos, M. Obrien, R.W. Bates, et al., Syngas-mediated C-C bond formation in flow: Selective rhodium-catalysed hydroformylation of styrenes, Synlett. (2011) 2648-2651. doi:10.1055/s-0031-1289292.

[42] B. Gutmann, P. Elsner, T. Glasnov, D.M. Roberge, C.O. Kappe, Shifting Chemical Equilibria in Flow-Efficient Decarbonylation Driven by Annular Flow Regimes, Angew. Chemie Int. Ed. 53 (2014) 11557-11561. doi:10.1002/anie.201407219.

[43] V.D. Pinho, B. Gutmann, L.S.M. Miranda, R.O.M. a. de Souza, C.O. Kappe, Continuous Flow Synthesis of alpha-Haloketones - Essential Building Blocks of Antiretroviral Agents, J. Org. Chem. (2014) 1555 - 1562. doi:10.1021/jo402849z.

[44] S.M. Lai, R. Martin-Aranda, K.L. Yeung, Knoevenagel condensation reaction in a membrane microreactor., Chem. Commun. (Camb). 1 (2003) 218-219. doi:10.1039/b209297b.

[45] P.D. Hampton, M.D. Whealon, L.M. Roberts, A. a. Yaeger, R. Boydson, Continuous organic synthesis in a spinning tube-in-tube reactor: TEMPO-catalyzed oxidation of alcohols by hypochlorite, Org. Process Res. Dev. 12 (2008) 946-949. doi:10.1021/op800051t.

[46] D. Cantillo, M. Baghbanzadeh, C.O. Kappe, In situ generated iron oxide nanocrystals as efficient and selective catalysts for the reduction of nitroarenes using a continuous flow method, Angew. 
Chemie - Int. Ed. 51 (2012) 10190-10193. doi:10.1002/anie.201205792.

[47] S. Ceylan, L. Coutable, J. Wegner, A. Kirschning, Inductive heating with magnetic materials inside flow reactors, Chem. - A Eur. J. 17 (2011) 1884-1893. doi:10.1002/chem.201002291.

[48] A. Molnàr, Efficient , Selective , and Recyclable Palladium Catalysts in Carbon - Carbon Coupling Reactions, Chem. Rev. 111 (2011) 2251-2320.

[49] L. Dalla-Vechia, B. Reichart, T. Glasnov, L.S.M. Miranda, C.O. Kappe, R.O.M. a de Souza, A three step continuous flow synthesis of the biaryl unit of the HIV protease inhibitor Atazanavir., Org. Biomol. Chem. 11 (2013) 6806-13. doi:10.1039/C3OB41464G.

[50] J. De M. Muñoz, J. Alcázar, A. De La Hoz, A. Díaz-Ortiz, Cross-coupling in flow using supported catalysts: Mild, clean, efficient and sustainable suzuki-miyaura coupling in a single pass, Adv. Synth. Catal. 354 (2012) 3456-3460. doi:10.1002/adsc.201200678.

[51] C. Deraedt, D. Astruc, "Homeopathic" Palladium Nanoparticle Catalysis of Cross Carbon-Carbon Coupling Reactions, Acc. Chem. Res. 47 (2014) 494 - 503.

[52] Z. Dong, Z. Ye, Reusable, Highly Active Heterogeneous Palladium Catalyst by Convenient SelfEncapsulation Cross-Linking Polymerization for Multiple Carbon $\square$ Carbon Cross-Coupling Reactions at ppm to ppb Palladium Loadings, Adv. Synth. Catal. 356 (2014) 3401-3414. doi:10.1002/adsc.201400520.

[53] R. Greco, W. Goessler, D. Cantillo, C.O. Kappe, Benchmarking Immobilized Di- and Triarylphosphine Palladium Catalysts for Continuous-Flow Cross-Coupling Reactions: E ffi ciency, Durability, and Metal Leaching Studies, ACS Catal. (2015). doi:10.1021/cs5020089.

[54] A. Manvar, A. Shah, Subtle Mitsunobu couplings under super-heating: the role of highthroughput continuous flow and microwave strategies, Org. Biomol. Chem. 12 (2014) 8112 8124. doi:10.1039/C4OB01432D.

[55] A. Nagaki, A. Kenmoku, Y. Moriwaki, A. Hayashi, J.I. Yoshida, Cross-coupling in a flow microreactor: Space integration of lithiation and murahashi coupling, Angew. Chemie - Int. Ed. 49 (2010) 7543-7547. doi:10.1002/anie.201002763.

[56] T. Noël, S.L. Buchwald, Cross-coupling in flow, Chem. Soc. Rev. 40 (2011) 5010. doi: $10.1039 / \mathrm{c} 1 \mathrm{cs} 15075 \mathrm{~h}$.

[57] D. Cantillo, C.O. Kappe, Immobilized Transition Metals as Catalysts for Cross-Couplings in Continuous Flow-A Critical Assessment of the Reaction Mechanism and Metal Leaching, ChemCatChem. 6 (2014) 3286 - 3305. doi:10.1002/cctc.201402483.

[58] K.M. Dawood, A. Kirschning, Combining enabling techniques in organic synthesis: solid-phaseassisted catalysis under microwave conditions using a stable Pd(II)-precatalyst, Tetrahedron. 61 (2005) 12121-12130. doi:10.1016/j.tet.2005.07.113.

[59] T. Noel, S. Kuhn, A.J. Musacchio, K.F. Jensen, S.L. Buchwald, Suzuki-miyaura cross-coupling 
reactions in flow: Multistep synthesis enabled by a microfluidic extraction, Angew. Chemie - Int. Ed. 50 (2011) 5943-5946. doi:10.1002/anie.201101480.

[60] V. Polshettiwar, Á. Molnár, Silica-supported Pd catalysts for Heck coupling reactions, Tetrahedron. 63 (2007) 6949-6976. doi:10.1016/j.tet.2007.04.023.

[61] A. Nagaki, Y. Takahashi, J.I. Yoshida, Extremely fast gas/liquid reactions in flow microreactors: Carboxylation of short-lived organolithiums, Chem. - A Eur. J. 20 (2014) 7931-7934. doi:10.1002/chem.201402520.

[62] T.N. Glasnov, C.O. Kappe, Toward a continuous-flow synthesis of Boscalid, Adv. Synth. Catal. 352 (2010) 3089-3097. doi:10.1002/adsc.201000646.

[63] T.P. Petersen, S. Mirsharghi, P.C. Rummel, S. Thiele, M.M. Rosenkilde, A. Ritzén, et al., Multistep continuous-flow synthesis in medicinal chemistry: Discovery and preliminary structure-activity relationships of CCR8 ligands, Chem. - A Eur. J. 19 (2013) 9343-9350. doi:10.1002/chem.201204350.

[64] T. Rodrigues, P. Schneider, G. Schneider, Accessing new chemical entities through microfluidic systems, Angew. Chemie - Int. Ed. 53 (2014) 5750-5758. doi:10.1002/anie.201400988.

[65] C.G. Frost, L. Mutton, Heterogeneous catalytic synthesis using microreactor technology, (2010) 1687-1703. doi:10.1039/c0gc00133c.

[66] R. Munirathinam, J. Huskens, W. Verboom, Supported Catalysis in Continuous-Flow Microreactors, Adv. Synth. Catal. 357 (2015) 1093-1123. doi:10.1002/adsc.201401081.

[67] A. Kirschning, W. Solodenko, K. Mennecke, Combining enabling techniques in organic synthesis: Continuous flow processes with heterogenized catalysts, Chem. - A Eur. J. 12 (2006) 5972-5990. doi:10.1002/chem.200600236.

[68] A. Gömann, J.A. Deverell, K.F. Munting, R.C. Jones, T. Rodemann, A.J. Canty, et al., Palladiummediated organic synthesis using porous polymer monolith formed in situ as a continuous catalyst support structure for application in microfluidic devices, Tetrahedron. 65 (2009) 1450-1454. doi:10.1016/j.tet.2008.12.007.

[69] A. Martinez-Lombardia, J. Krinsky, I. Peñafiel, S. Castillón, K. Loponov, A. Lapkin, et al., Heterogenization of Pd-NHC complexes onto a silica support and their application in the SuzukiMiyaura coupling under batch and continuous flow conditions, Catal. Sci. Technol. 5 (2015) 310 319. doi:10.1039/C4CY00829D.

[70] K. Mennecke, W. Solodenko, A. Kirschning, Carbon-carbon cross-coupling reactions under continuous flow conditions using poly(vinylpyridine) doped with palladium, Synthesis (Stuttg). 10 (2008) 1589-1599. doi:10.1055/s-2008-1072579.

[71] C. Pavia, E. Ballerini, L.A. Bivona, F. Giacalone, C. Aprile, L. Vaccaro, et al., Palladium supported on cross-linked imidazolium network on silica as highly sustainable catalysts for the 
Suzuki reaction under flow conditions, Adv. Synth. Catal. 355 (2013) 2007-2018. doi:10.1002/adsc. 201300215.

[72] K. Hashimoto, N. Kumagai, M. Shibasaki, A Carbon Nanotube Confinement Strategy to Implement Homogeneous Asymmetric Catalysis in the Solid Phase, Chem. - A Eur. J. 21 (2015) 4262-4266. doi:10.1002/chem.201406402.

[73] K. Hashimoto, N. Kumagai, M. Shibasaki, Self-assembled asymmetric catalyst engaged in a continuous-flow platform: An anti -selective catalytic asymmetric nitroaldol reaction, Org. Lett. 16 (2014) 3496-3499. doi:10.1021/ol501432h.

[74] P. He, S.J. Haswell, P.D.I. Fletcher, S.M. Kelly, A. Mansfield, Scaling up of continuous-flow, microwave-assisted, organic reactions by varying the size of Pd-functionalized catalytic monoliths, Beilstein J. Org. Chem. 7 (2011) 1150-1157. doi:10.3762/bjoc.7.133.

[75] I.R. Baxendale, The integration of flow reactors into synthetic organic chemistry, J. Chem. Technol. Biotechnol. 88 (2013) 519-552. doi:10.1002/jctb.4012.

[76] B. Urbán, D. Srankó, G. Sáfrán, L. Ürge, F. Darvas, J. Bakos, et al., Evaluation of SILP-Pd catalysts for Heck reactions in a microfluidics-based high throughput flow reactor, J. Mol. Catal. A Chem. 395 (2014) 364-372. doi:10.1016/j.molcata.2014.08.031.

[77] W. Solodenko, H. Wen, S. Leue, F. Stuhlmann, G. Sourkouni-Argirusi, G. Jas, et al., Development of a continuous-flow system for catalysis with palladium(0) particles, European J. Org. Chem. (2004) 3601-3610. doi:10.1002/ejoc.200400194.

[78] T.N. Glasnov, S. Findenig, C.O. Kappe, Heterogeneous Versus Homogeneous Palladium Catalysts for Ligandless Mizoroki - Heck Reactions : A Comparison of Batch / Microwave and Continuous-Flow Processing, Chem. - A Eur. J. 15 (2009) 1001-1010. doi:10.1002/chem.200802200.

[79] N.T.S. Phan, M. Van Der Sluys, C.W. Jones, On the nature of the active species in palladium catalyzed Mizoroki-Heck and Suzuki-Miyaura couplings - Homogeneous or heterogeneous catalysis, a critical review, Adv. Synth. Catal. 348 (2006) 609-679. doi:10.1002/adsc.200505473.

[80] W.R. Reynolds, P. Plucinski, C.G. Frost, Robust and reusable supported palladium catalysts for cross-coupling reactions in flow, Catal. Sci. Technol. 4 (2014) 948. doi:10.1039/c3cy00836c.

[81] J.M. Richardson, C.W. Jones, Strong evidence of solution-phase catalysis associated with palladium leaching from immobilized thiols during Heck and Suzuki coupling of aryl iodides, bromides, and chlorides, J. Catal. 251 (2007) 80-93. doi:10.1016/j.jcat.2007.07.005.

[82] S.C. Stouten, T. Noël, Q. Wang, V. Hessel, Supported Liquid Phase Catalyst coating in micro flow Mizoroki-Heck reaction, Chem. Eng. J. 279 (2015) 143-148. doi:10.1016/j.cej.2015.05.026.

[83] S.C. Stouten, Q. Wang, T. Noël, V. Hessel, A supported aqueous phase catalyst coating in micro flow Mizoroki-Heck reaction, Tetrahedron Lett. $54 \quad$ (2013) 2194-2198. 
doi:10.1016/j.tetlet.2013.02.064.

[84] K.K. Hii, K. Hellgardt, Catalysis in Flow: Why Leaching Matters, Top. Organomet. Chem. (2015) 1-14. doi:10.1007/3418_2015_149.

[85] C. Rodríguez-Escrich, M. a. Pericàs, Organocatalysis on Tap: Enantioselective Continuous Flow Processes Mediated by Solid-Supported Chiral Organocatalysts, European J. Org. Chem. 2015 (2015) 1173-1188. doi:10.1002/ejoc.201403042.

[86] I. Vural Gürsel, T. Noel, Q. Wang, V. Hessel, Separation/Recycling Methods of Homogeneous Transition Metal Catalysts in Continuous Flow, Green Chem. 17 (2015) 2012-2026. doi:10.1039/C4GC02160F.

[87] K.S. Elvira, R.C.R. Wootton, N.M. Reis, M.R. Mackley, A.J. DeMello, Through-wall mass transport as a modality for safe generation of singlet oxygen in continuous flows, ACS Sustain. Chem. Eng. 1 (2013) 209-213. doi:10.1021/sc300093j.

[88] Y. Su, N.J.W. Straathof, V. Hessel, T. Noël, Photochemical transformations accelerated in continuous-flow reactors: Basic concepts and applications, Chem. - A Eur. J. 20 (2014) 1056210589. doi:10.1002/chem.201400283.

[89] D. Šterk, M. Jukič, Z. Časar, Application of flow photochemical bromination in the synthesis of a 5-bromomethylpyrimidine precursor of rosuvastatin: Improvement of productivity and product purity, Org. Process Res. Dev. 17 (2013) 145-151. doi:10.1021/op300248y.

[90] J.W. Tucker, Y. Zhang, T.F. Jamison, C.R.J. Stephenson, Visible-light photoredox catalysis in flow, Angew. Chemie - Int. Ed. 51 (2012) 4144-4147. doi:10.1002/anie.201200961.

[91] F. Lévesque, P.H. Seeberger, Continuous-flow synthesis of the anti-malaria drug artemisinin, Angew. Chemie - Int. Ed. 51 (2012) 1706-1709. doi:10.1002/anie.201107446.

[92] M.D. Konieczynska, C. Dai, C.R.J. Stephenson, Synthesis of symmetric anhydrides using visible light-mediated photoredox catalysis, Org. Biomol. Chem. 10 (2012) 4509. doi:10.1039/c2ob25463h.

[93] D. Wang, Y. Li, W. Zhang, Q. Wang, P. Wang, C. Wang, Development and modeling of a flat plate serpentine reactor for photocatalytic degradation of 17-ethinylestradiol, Environ. Sci. Pollut. Res. 20 (2013) 2321-2329. doi:10.1007/s11356-012-1107-6.

[94] S. Horikoshi, T. Sumi, N. Serpone, A hybrid microreactor/microwave high-pressure flow system of a novel concept design and its application to the synthesis of silver nanoparticles, Chem. Eng. Process. Process Intensif. 73 (2013) 59-66. doi:10.1016/j.cep.2013.07.009.

[95] D. Prieling, H. Steiner, Analysis of the wall mass transfer on spinning disks using an integral boundary layer method, Chem. Eng. Sci. 101 (2013) 109-119. doi:10.1016/j.ces.2013.06.034.

[96] G.L. Chiarello, I. Rossetti, L. Forni, P. Lopinto, G. Migliavacca, Solvent nature effect in preparation of perovskites by flame pyrolysis. 2. Alcohols and alcohols + propionic acid mixtures, 
Appl. Catal. B Environ. 72 (2007) 227-232. doi:10.1016/j.apcatb.2006.10.026.

[97] G.L. Chiarello, I. Rossetti, L. Forni, P. Lopinto, G. Migliavacca, Solvent nature effect in preparation of perovskites by flame-pyrolysis. 1. Carboxylic acids, Appl. Catal. B Environ. 72 (2007) 218-226. doi:10.1016/j.apcatb.2006.11.001.

[98] G.L. Chiarello, I. Rossetti, L. Forni, Flame-spray pyrolysis preparation of perovskites for methane catalytic combustion, J. Catal. 236 (2005) 251-261.

[99] G.L. Chiarello, I. Rossetti, P. Lopinto, G. Migliavacca, L. Forni, Preparation by flame spray pyrolysis of ABO3 catalysts for the flameless combustion of methane, Catal. Today. 117 (2006) 549-553. doi:10.1016/j.cattod.2006.06.018.

[100] L. Forni, I. Rossetti, Catalytic combustion of hydrocarbons over perovskites, Appl. Catal. B Environ. 38 (2002) 29-37.

[101] R. Leanza, I. Rossetti, L. Fabbrini, C. Oliva, L. Forni, Perovskite catalysts for the catalytic flameless combustion of methane. Preparation by flame-hydrolysis and characterisation by TPDTPR-MS and EPR, Appl. Catal. B Environ. 28 (2000) 55-64. doi:10.1016/S0926-3373(00)001636.

[102] X. Chen, M. Arruebo, K.L. Yeung, Flow-synthesis of mesoporous silicas and their use in the preparation of magnetic catalysts for Knoevenagel condensation reactions, Catal. Today. 204 (2013) 140-147. doi:10.1016/j.cattod.2012.07.017.

[103] T.N. Ng, X.Q. Chen, K.L. Yeung, Direct manipulation of particle size and morphology of ordered mesoporous silica by flow synthesis, RSC Adv. 5 (2015) 13331-13340. doi:10.1039/C4RA16679E.

[104] Z. Anxionnaz-Minvielle, M. Cabassud, C. Gourdon, P. Tochon, Influence of the meandering channel geometry on the thermo-hydraulic performances of an intensified heat exchanger/reactor, Chem. Eng. Process. Process Intensif. 73 (2013) 67-80. doi:10.1016/j.cep.2013.06.012.

[105] N. Kockmann, M. Gottsponer, B. Zimmermann, D.M. Roberge, Enabling continuous-flow chemistry in microstructured devices for pharmaceutical and fine-chemical production, Chem. A Eur. J. 14 (2008) 7470-7477. doi:10.1002/chem.200800707.

[106] N. Kockmann, D.M. Roberge, Scale-up concept for modular microstructured reactors based on mixing, heat transfer, and reactor safety, Chem. Eng. Process. Process Intensif. 50 (2011) 10171026. doi:10.1016/j.cep.2011.05.021.

[107] B.C. Masters, T.P. Garvin, C.M. Mitsingas, K.B. Ford, C.P. Marsh, Design and manufacture of a microchannel plasma reactor by CNC milling, Microelectron. Eng. 136 (2015) 51-56. doi:10.1016/j.mee.2015.03.052.

[108] K.D. Nagy, B. Shen, T.F. Jamison, K.F. Jensen, Mixing and dispersion in small-scale flow systems, Org. Process Res. Dev. 16 (2012) 976-981. doi:10.1021/op200349f. 
[109] P. Plouffe, D.M. Roberge, A. Macchi, Liquid-liquid flow regimes and mass transfer in various micro-reactors, Chem. Eng. J. (2014). doi:10.1016/j.cej.2014.10.072.

[110] K. Wang, Y. Lu, G. Luo, Strategy for Scaling-up of a Microsieve Dispersion Reactor, Chem. Eng. Technol. 37 (2014) 2116-2122. doi:10.1002/ceat.201400296.

[111] J.B. You, K. Kang, T.T. Tran, H. Park, W.R. Hwang, J.M. Kim, et al., PDMS-based turbulent microfluidic mixer, Lab Chip. 15 (2015) 1727-1735. doi:10.1039/C5LC00070J.

[112] R.L. Hartman, J.P. McMullen, K.F. Jensen, Deciding whether to go with the flow: Evaluating the merits of flow reactors for synthesis, Angew. Chemie - Int. Ed. 50 (2011) 7502-7519. doi:10.1002/anie.201004637.

[113] C.P. Holvey, D.M. Roberge, M. Gottsponer, N. Kockmann, A. Macchi, Pressure drop and mixing in single phase microreactors: Simplified designs of micromixers, Chem. Eng. Process. Process Intensif. 50 (2011) 1069-1075. doi:10.1016/j.cep.2011.05.016.

[114] M. Irfan, T.N. Glasnov, C.O. Kappe, Heterogeneous catalytic hydrogenation reactions in continuous-flow reactors, ChemSusChem. 4 (2011) 300-316. doi:10.1002/cssc.201000354.

[115] N.-T. Nguyen, Z. Wu, Micromixers - a review, J. Micromechanics Microengineering. 15 (2005) R1-R16. doi:10.1088/0960-1317/15/2/R01.

[116] C. Lee, W. Wang, C. Liu, L. Fu, Passive Mixers in Microfluidic Systems: A Review by Department of Mechanical and Computer-Aided Engineering, Department of Food Science , Department of Biomechatronics Engineering, Corresponding author: Prof . Lung-Ming Fu, Chem. Eng. J. 288 (2015) 146-160. doi:10.1016/j.cej.2015.10.122.

[117] Valery Rudyak, A. Minakov, Modeling and optimization of an, Micromachines. 33 (2009) 7588. doi:10.3390/mi5040886.

[118] A. Elagli, S. Laurette, A. Treizebre, B. Bocquet, R. Froidevaux, Diffusion based kinetic selectivity modulation of enzymatic proteolysis in a microfluidic reactor: experimental analysis and stochastic modeling, RSC Adv. 4 (2014) 3873-3882. doi:10.1039/C3RA46005C.

[119] J. Bao, G.K. Tranmer, The utilization of copper flow reactors in organic synthesis, Chem. Commun. 51 (2015) 3037-3044. doi:10.1039/C4CC09221J.

[120] T. Noël, Y. Su, V. Hessel, Beyond Organometallic Flow Chemistry: The Principles Behind the Use of Continuous-Flow Reactors for Synthesis, Top. Organomet. Chem. (2015) 1-41. doi:10.1007/3418_2015_152.

[121] P. Plouffe, A. Macchi, D.M. Roberge, From Batch to Continuous Chemical Synthesis-A Toolbox Approach, Org. Process Res. Dev. 18 (2014) 141001103047004. doi:10.1021/op5001918.

[122] C.R. Boehm, P.S. Freemont, O. Ces, Design of a prototype flow microreactor for synthetic biology in vitro., Lab Chip. 13 (2013) 3426-32. doi:10.1039/c3lc50231g. 
[123] A.J. Capel, S. Edmondson, S.D.R. Christie, R.D. Goodridge, R.J. Bibb, M. Thurstans, Design and additive manufacture for flow chemistry., Lab Chip. 13 (2013) 4583-90. doi:10.1039/c3lc50844g.

[124] A.B. Leduc, T.F. Jamison, Continuous flow oxidation of alcohols and aldehydes utilizing bleach and catalytic tetrabutylammonium bromide, Org. Process Res. Dev. 16 (2012) 1082-1089. doi:10.1021/op200118h.

[125] J.P. Kruth, L. Froyen, J. Van Vaerenbergh, P. Mercelis, M. Rombouts, B. Lauwers, Selective laser melting of iron-based powder, J. Mater. Process. Technol. 149 (2004) 616-622. doi:10.1016/j.jmatprotec.2003.11.051.

[126] E. Louvis, P. Fox, C.J. Sutcliffe, Selective laser melting of aluminium components, J. Mater. Process. Technol. 211 (2011) 275-284. doi:10.1016/j.jmatprotec.2010.09.019.

[127] L. Rinaldi, D. Carnaroglio, L. Rotolo, G. Cravotto, A Microwave-Based Chemical Factory in the Lab : From Milligram to Multigram Preparations, J. Chem. (2015) 1-8.

[128] http://ats-scientific.com/products/flowsynth-continuous-flow-microwave-reactor, (n.d.).

[129] R. Morschhäuser, M. Krull, C. Kayser, C. Boberski, R. Bierbaum, P. a. Püschner, et al., Microwave-assisted continuous flow synthesis on industrial scale, Green Process. Synth. 1 (2012) 281-290. doi:10.1515/gps-2012-0032.

[130] M. Cabrera, O. Alfano, A. Cassano, Novel reactor for photocatalytic kinetic studies, Ind. Eng. Chem. Res. 33 (1994) 3031-3042. doi:10.1021/ie00036a019.

[131] I. Rossetti, A. Villa, C. Pirola, L. Prati, G. Ramis, A novel high-pressure photoreactor for CO2 photoconversion to fuels, RSC Adv. 4 (2014) 28883-28885. doi:10.1039/C4RA03751K.

[132] I. Rossetti, A. Villa, M. Compagnoni, L. Prati, G. Ramis, C. Pirola, et al., CO2 photoconversion to fuels under high pressure: effect of $\mathrm{TiO} 2$ phase and of unconventional reaction conditions, Catal. Sci. Technol. 5 (2015) 4481 - 4487. doi:10.1039/C5CY00756A.

[133] B.G. Anderson, W.E. Bauta, W.R. Cantrell, Development of an improved process for doxercalciferol via a continuous photochemical reaction, Org. Process Res. Dev. 16 (2012) 967975. doi:10.1021/op200346g.

[134] M. Vicevic, K.V.K. Boodhoo, K. Scott, Catalytic isomerisation of $\alpha$-pinene oxide to campholenic aldehyde using silica-supported zinc triflate catalysts, Chem. Eng. J. 133 (2007) 43-57. doi:10.1016/j.cej.2006.12.003.

[135] N.F. Badham, W.L. Mendelson, A. Allen, A.M. Diederich, D.S. Eggleston, J.J. Filan, et al., Rearrangement of epoxynitriles: A convenient homologation of acyclic and cyclic ketones to carboxylic acids, J. Org. Chem. 67 (2002) 5440-5443. doi:10.1021/jo025737g.

[136] K. Somerville, M. Tilley, G. Li, D. Mallik, M.G. Organ, A Flow Reactor with Inline Analytics : Design and Implementation, Org. Process Res. Dev. 18 (2014) 1315 - 1320. 
[137] K.F. Jensen, B.J. Reizman, S.G. Newman, Tools for chemical synthesis in microsystems., Lab Chip. 14 (2014) 3206-3212. doi:10.1039/c4lc00330f.

[138] Y. Su, K. Kuijpers, V. Hessel, T. Noël, A convenient numbering-up strategy for the scale-up of gas-liquid photoredox catalysis in flow, React. Chem. Eng. (2016). doi:10.1039/C5RE00021A.

[139] D. Cantillo, O. De Frutos, J. a. Rincon, C. Mateos, C. Oliver Kappe, A scalable procedure for light-induced benzylic brominations in continuous flow, J. Org. Chem. 79 (2014) 223-229. doi:10.1021/jo402409k.

[140] E. Shahbazali, M. Spapens, H. Kobayashi, S. Ookawara, T. Noël, V. Hessel, Connected nucleophilic substitution-Claisen rearrangement in flow - Analysis for kilo-lab process solutions with orthogonality, Chem. Eng. J. 281 (2015) 144-154. doi:10.1016/j.cej.2015.06.020.

[141] Y. Zhang, S.C. Born, K.F. Jensen, Scale-Up Investigation of the Continuous Phase-TransferCatalyzed Hypochlorite Oxidation of Alcohols and Aldehydes, Org. Process Res. Dev. 18 (2014) 1476-1481. doi:10.1021/op500158h.

[142] F.J. Keil, Modeling of Process Intensification - An Introduction and Overview, Wiley-VCH Verlag GmbH \& Co. KGaA, 2007.

[143] D. Reay, C. Ramshaw, Process Intensification. Engineering for Efficiency, Sustainability and Flexibility, Elsevier Ltd., 2008.

[144] T. Aillet, K. Loubie, O. Dechy-cabaret, L. Prat, Microreactors as a Tool for Acquiring Kinetic Data on Photochemical Reactions, Chem. Eng. 39 (2016) 115-122. doi:10.1002/ceat.201500163.

[145] Y. Su, V. Hessel, T. Noël, A compact photomicroreactor design for kinetic studies of gas-liquid photocatalytic transformations, AIChE J. 61 (2015) 2215 -2227.

[146] N. Kockmann, D.M. Roberge, Harsh reaction conditions in continuous-flow microreactors for pharmaceutical production, Chem. Eng. Technol. 32 (2009) 1682-1694. doi:10.1002/ceat.200900355.

[147] J.A. Newby, L. Huck, D.W. Blaylock, P.M. Witt, S. V. Ley, D.L. Browne, Investigation of a lithium-halogen exchange flow process for the preparation of boronates by using a cryo-flow reactor, Chem. - A Eur. J. 20 (2014) 263-271. doi:10.1002/chem.201303736.

[148] J.A. Newby, D.W. Blaylock, P.M. Witt, J.C. Pastre, M.K. Zacharova, S. V Ley, et al., Design and Application of a Low-Temperature Continuous Flow Chemistry Platform, Org. Process Res. Dev. 18 (2014) 1211 - 1220. dx.doi.org/10.1021/op500213j.

[149] D. Roberge, C. Noti, E. Irle, M. Eyholzer, B. Rittiner, G. Penn, et al., Control of Hazardous Processes in Flow: Synthesis of 2-Nitroethanol, J. Flow Chem. 4 (2013) 1-9. doi:10.1556/JFCD-13-00016.

[150] H.P.L. Gemoets, Y. Su, M. Shang, V. Hessel, R. Luque, T. Noël, Liquid phase oxidation chemistry in continuous-flow microreactors, Chem. Soc. Rev. 45 (2015). 
doi:10.1039/C5CS00447K.

[151] B. Pieber, C.O. Kappe, Aerobic Oxidations in Continuous Flow, Top. Organomet. Chem. (2015) 1 - 40. doi:10.1007/3418_2015_133.

[152] I. Vural Gürsel, F. Aldiansyah, Q. Wang, T. Noël, V. Hessel, Continuous metal scavenging and coupling to one-pot copper-catalyzed azide-alkyne cycloaddition click reaction in flow, Chem. Eng. J. 270 (2015) 468-475. doi:10.1016/j.cej.2015.02.035.

[153] N. Zotova, F.J. Roberts, G.H. Kelsall, A.S. Jessiman, K. Hellgardt, K.K. (Mimi) Hii, Catalysis in flow: Au-catalysed alkylation of amines by alcohols, Green Chem. 14 (2012) 226. doi:10.1039/c1gc16118k.

[154] B. Ahmed-Omer, J.C. Brandt, T. Wirth, Advanced organic synthesis using microreactor technology., Org. Biomol. Chem. 5 (2007) 733-740. doi:10.1039/b615072a.

[155] F. Alonso, I.P. Beletskaya, M. Yus, Non-conventional methodologies for transition-metal catalysed carbon-carbon coupling: a critical overview. Part 2: The Suzuki reaction, Tetrahedron. 64 (2008) 3047-3101. doi:10.1016/j.tet.2007.12.036.

[156] B. Pieber, T. Glasnov, C.O. Kappe, Continuous Flow Reduction of Artemisinic Acid Utilizing Multi-Injection Strategies - Closing the Gap Towards a Fully Continuous Synthesis of Antimalarial Drugs, Chem. - A Eur. J. 21 (2015) 4368 - 4376. doi:10.1002/chem.201406439. 